\title{
Artículos
}

\section{Una agenda de reforma electoral para El Salvador}

\author{
Álvaro Artiga-González'
}

Resumen
En este trabajo, el autor propone una serie de temas para una
posible agenda de reforma electoral. Con tal fin, primero establece
la óptica desde la que hace la propuesta y sugiere que antes que
cualquier debate sobre medidas concretas de reforma se definan los
objecivos políticos de ésta. Posteriormente hace un análisis de los
sistemas empleados para las elecciones presidenciales, legislativas y
de concejos municipales, suponiendo como objetivos políticos el
mejoramiento del carácter representativo de los puestos sometidos
a elección pública, tanto en términos de proporcionalidad como
de relación entre representantes y representados. Finalmente, con
el diagnóstico elaborado, concluye proponiendo los puntos de la
agenda.

\section{Introducción}

Después de las elecciones generales de 1994, los que entonces fueran los dos principales candidatos a la presidencia de la República - Armando Calderón Sol, del partido ARENA, y Rubén Zamora, de la coalición FMLN-CD-MNR- firmaron un acuerdo mediante el cual se compromelían a impulsar una serie de reformas electorales que evitaran, los que ya para entonces constituían, una tradición de anormalidades e irregularidades en los procesos electorales. Aquellas "elecciones del siglo" vigiladas por una miríada de observadores nacionales $e$ internacionales, $y$ aunque suficientemente aceptadas como libres y competitivas, no estuvieron ajenas a problemas de organización y de logística. Desde entonces, ciertamente ya no como cumplimiento del compromiso asumido ante los oficios mediadores de la División Electoral de la Misión de Observadores de Naciones Unidas para El Salvador (ONUSAL), se han venido proponiendo y decretando reformas puntuales especialmente a específicos artículos del Código Electoral. Sin embargo, los tres procesos electorales si-

1. Profesor e Investigador del Departamento de Sociología y Ciencias Políticas de la UCA. Doctor en Ciencia Política por la Universidad de Salamanca, España. 
guientes $(1997,1999$ y 2000) volvieron a verse afectados por problemas semejantes a los de 1994 con el consiguiente desgaste procedimental. En la medida que el abstencionismo y la pérdida de credibilidad entre la ciudadanía ha ido incrementándose, las voces que piden una reforma electoral integral han ido ganando terreno en el espacio público. El mismo Tribunal Supremo Electoral -máxima autoridad en materia electoral- está empeñado en un proceso de modernización de sí mismo reconociendo asi la necesidad de la reforma. También voces "independientes" como las del Movimiento Independiente pro Reforma Electoral (MIRE) y las del Consorcio de Organizaciones Ciudadanas promueven y consideran que es el momento oportuno - de acuerdo con el calendario electoral- para echar adelante la Reforma. Convencido de que nuestro sistema electoral es mejorable, en este trabajo presentaré parte de lo que años de investigación y seguimiento al tema me permiten definir una serie de puntos de agenda para la Reforma.

\section{Una propuesta desde la ciencia política}

Antes de seguir adelante quiero dejar constancia de la perspectiva desde la que hago mi propuesta. Utilizaré herramientas analíticas provenientes del campo de la ciencia política. Esto lo podrá notar cualquier lector conocedor de este campo. El diagnóstico que presentaré intenta dar cuenta de la complejidad del tema y de los intereses que están en juego. Como pretendo mostrar en su momento, la reforma electoral no es un problema únicamente de carácter técnico. Es también un problema político. Pero aún en este terreno, el juicio político puede ser errado si se basa en un diagnóstico falso o simplista.

\subsection{Sistema electoral y derecho electoral}

La selección entre la oferta electoral - los partidos políticos que compiten electoralmente- se lleva a cabo en un marco institucional que termina caracterizando el sistema político de la nación. Ese marco institucional constituye todo un entramado de normas formales e informales que regulan y hacen previsible el comportamiento electoral de los diversos actores. Tómese en cuenta que los votantes optan por ofertas partidistas dentro de los límites establecidos por el derecho electoral y el resultado se define según la sistemática electoral. Existe pues, una distinción entre derecho y sistema electoral. Este último puede definirse como el conjunto de elementos de la normativa electoral que, con eficacia directa, inciden en la traducción o transformación de las preferencias electorales (votos emitidos) en cuotas de poder político institucionalizado (escaños o cargos electivos). El sistema electoral es parte del derecho electoral. Pero éste incluye otros elementos que no son parte del sistema electoral. De allí que una reforma puede modificar algunas normas sin que por ello se afecte necesariamente al sistema electoral. Esta distinción es la que me permite hacer un diagnóstico y proponer una agenda de reforma que efectivamente afecte al sistema electoral y por esta vía a la traducción de votos en distribución de cuotas de poder institucionalizado.

Por otra parte, en regímenes democráticos, el derecho electoral entendido como derecho de sufragio se fundamenta en cuatro principios orientados a que el voto sea universal, igual, directo y secreto (Nohlen, 1994). Si estos principios están garantizados por la normativa electoral contenida, por ejemplo, en los diversos artículos del Código Electoral, el funcionamiento real del sistema electoral no debe atentar contra dichos principios². Al señalar este caso pretendo ilustrar cómo algunas veces puede llegar a plantearse la necesidad de reformar no tanto una norma, sino el funcionamiento real de un diseño institucional. Como tendremos oportunidad de ver más adelante, el principio de igualdad del voto para las elecciones de diputados es uno de los que se ven más seriamente amenazados en nuestro país. No está de más decir que de esta situación sacan provecho algunos partidos políticos para obtener mayores cuotas de poder que las que proporcionalmente les correspondería atendiendo al caudal de votos acumulados.

\subsection{Los componentes del sistema electoral}

En la literatura politológica es frecuente la consideración de los sistemas electorales a la luz de los votos emitidos. Por eso la insistencia en esta literatura en la traducción de los votos en escaños. El análisis recae en aquellos elementos que,

2. De hecho, el artículo 3 del Código Elecioral establece claramente que además de ser un derecho y un deber de los ciudadanos "cl voto es libre, dirccio, igualitario y secreto". Se recoge aquí lo normado por la Constilución Política en el artículo 78 adquiriendo así estos cuatro principios el rango constitucional. 
una vez emitidos los votos, producen un resultado específico en términos de reparto de cuotas de poder. Poco o nada se dice, o se considera, sobre los elementos que inciden en el número de votos que luego son traducidos en escaños. Probablemente esto se debe a que dicha literatura es producida cara a democracias consolidadas donde las reglas del juego están claras y ampliamente aceptadas. Este no es el caso salvadoreño, donde buena parte de la organización de los procesos electorales inciden en la mayor o menor asistencia a ejercer el sufragio por parte de la ciudadanía. Esta es una de las razones por las cuales, además de los elementos normalmente aceptados por la comunidad politológica como parte del sistema electoral, he de añadir otros elementos ad hoc, si se quiere, al caso salvadoreño.

¿Cuáles son los elementos que usualmente los politólogos consideran constituyentes de los sistemas electorales? Existe un amplio consenso entre los científicos de la política al señalar como elementos constitutivos o configuradores de los sistemas electorales, los siguientes: $(a)$ número de representantes a elegir, $(b)$ distribución de las circunscripciones o distritos electorales, (c) formas de la candidatura, $(d)$ formas de expresión del voto o procedimientos de votación, $(e)$ barreras y $(f)$ fórmula electoral.

El número de representantes a elegir se puede establecer bien como un número fijo o bien de en regímenes democráticos, el derecho electoral entendido como derecho de sufragio se fundamenta en cuatro principios orientados a que el voto sea universal, igual, directo y secreto (Nohlen, 1994). minales. otorgados en otras zonas. En algunos lugares, las circunscripciones son conocidas como distritos electorales. Si bien es cierto que es usual que las circunscripciones correspondan a la división administrativa-territorial del país, no es necesario que esto sea siempre así. Es perfectamente posible diseñar una división en distritos electorales diferente a la división administrativa-territorial. Una medida así sería recomendable cuando por seguir esta división las circunscripciones resultan tales que provocan sobrerrepresentación de algunos partidos ${ }^{3}$.

Las formas de candidatura o tipos de listas corresponden a la forma en que son presentadas las personas que compiten por el voto de los y las electores ${ }^{4}$. Así podemos tener candidaturas individuales - normalmente asociadas a circunscripciones uninominales - y candidaturas de lista, donde se establece la relación de candidatos y candidatas que se presentan a la elección en la misma circunscripción - razón por la cual este tipo de candidatura se asocia con circunscripciones plurino-

Por olra parte, las listas pueden ser de tres tipos: listas cerradas y bloqueadas -donde cada partido presenta su lista y el orden de los candidatos y candidatas es invariable. El electorado vota la lista pero los escaños se atribuyen en el orden fijado en la lista; listas cerradas pero no bloqueadas -donde el electorado puede ordenar la lista aunque no puede acuerdo con una relación, ya sea entre escaños y electores o ya sea entre escaños y habilantes. Este número se conoce como el tamaño o magnitud $(M)$ de las circunscripciones electorales. Si se elige un único representante, entonces la circunscripción es uninominal. Si $M$ es mayor que 1 , entonces estamos ante circunscripciones plurinominales.

Las circunscripciones son aquellas zonas en las cuales los votos emitidos por los electores constituyen la base para el reparto de los escaños con independencia de los votos que hayan sido agregar candidatos o candidatas; y listas abiertas -donde el electorado puede modificar el orden, combinar candidatos o candidatas de diferentes partidos e incluso puede agregar nucvas candidaturas. Como puede apreciarse, cada uno de estos lipos de lista of rece diferentes posibilidades de influencia a los y las electores más allá del mero hecho de votar. La influencia es mayor en las listas abierlas y menor en las listas cerradas y bloqueadas.

En cuanto al procedimiento de votación se habla de voto único cuando el electorado emite un

3. Algo que es frecuente cuando las circunscripciones son pequeñas como las ocho circunscripciones que en El Salvador tienen asignados tres diputados. Más adelante profundizaremos en este punto.

4. Las listas son las mismas planillas de candidatos. 
solo voto independientemente de los candidatos o candidatas a elegir en la circunscripción. En cambio cuando los y las electores tienen la posibilidad de emitir su voto a favor de varias candidaturas se trata de un voto múltiple. Existe también la posibilidad de que el o la votante, ante una lista cerrada pero no bloqueada, pueda alterar el orden de las candidaturas. En este caso se habla de un voto preferencial. Cuando los y las votantes pueden incluso combinar candidatos de diferentes listas - abiertas -, estamos ante lo que se denomina voto combinado o "panachage". Entre formas de candidatura y procedimientos de votación se puede establecer las relaciones mostradas en la Gráfica 1.

\section{Gráfica 1 \\ Relaciones entre formas de candidatura y procedimientos de votación}

\section{Lista cerrada y bloqueada $\longrightarrow$ voto único \\ Lista cerrada y no bloqueada $\longrightarrow$ voto preferencial \\ Lista abierta $\longrightarrow$ voto combinado o "panachage" \\ Candidatura unipersonal $\longrightarrow$ voto único}

Para que un partido político cualquiera pueda obtener escaños parlamentarios e incluso mantener su misma existencia o registro legal usualmente se le exige, mediante disposiciones especiales en la ley electoral, que alcance un umbral mínimo de votos. Este umbral constituye una barrera. Su de- finición no sólo obedece a criterios técnicos, sino también puede obedecer a criterios políticos. Por ejemplo, elevar las barreras puede tener la finalidad de mantener baja la fragmentación del sistema de partidos. Además, cuanto más altas son las barreras mayores efectos reductores en el número de partidos que alcanzan escaños tiene el sistema ${ }^{5}$. Ahora bien, la barrera puede ser establecida no tanto como porcentaje del número de votos obtenidos. Podría definirse como un límite para el número de veces que un partido se abstiene, por diversas razones, a participar en las elecciones. En este caso se trataría de una barrera que apunta no hacia el ingreso al reparto de los escaños, sino a favorecer la estabilidad de la oferta partidista ante la que tienen que optar las y los electores.

Las barreras pueden ser legales cuando están estipuladas explícitamente en la ley electoral". Pero también pueden ser barreras teóricas que si bien no eliminan legalmente a ningún partido de la competencia electoral, así como tampoco impiden legalmente el acceso al reparto de escaños, sí que funcionan como filtros prácticos para entrar a este reparto. Estas barreras -llamadas también umbrales de representación (Nohlen, 1994) - son un efecto práctico, no regulado jurídicamente, del sistema electoral. Es posible demostrar que aunque no existan barreras legales para ingresar al reparto de escaños, no todos los partidos obtienen escaño alguno?.

Por otra parte, en países como El Salvador que combina varios sistemas electorales - según el nivel de disputa política: presidencial, legislativo, de concejos municipales-, las barreras legales defi-

5. Esta afirmación no siempre se cumple, pues el efecto reductor también depende de la política de alianzas electorales que lleven a cabo los partidos. Sin embargo, tal afirmación es válida como lendencia.

6. El Código Electoral salvadoreño establece varias barreras cuando en el artículo $182 \mathrm{se}$ regula la cancelación de un partido. Así, en el numeral 3 sc cslablece que procede la cancclación "Cuando un Partido Político que interviene en una elección de Presidente y Vicepresidente de la República o de Diputados en la Asamblea Lcgislativa y no obienga por lo menos el tres por ciento del total de los votos válidos en la clección en que dicho Partido haya participado". En cl numeral 7 sc cstablecc que dicha cancclación tambićn proccde "Cuando los Partidos Politicos que integren una cóalición para participar en una elección de Presidente y Vicepresidente de la República, o de Diputados a la Asamblea Legislativa, participen con símbolo único, y no obtuvieren en cada una de cllas, el porcentaje de volos válidos scgún la siguiente tabla: a) El 6 por ciento si la COALICIÓN está integrada por dos Partidos Políticos; b) El 9 por ciento si la COALICIÓN está integrada por tres Partidos Políticos, y c) El 1 por ciento adicional por cada Partido Político superior a tres que integren o pacien conformar dicha COALICIÓN. Cuando la COALICIÓN rucsc pactada con símbolo propio, y aquel o aquellos partidos coaligados que no obtengan por lo menos el 3 por ciento de los votos válidos emitidos".

7. Otra barrera no regulada jurídicamentc es la llamada break-even point, que establece el umbral de votos necesario para alcanzar una proporción de cscaños mayor que la proporción de volos. A parlir de cse punto, cl partido o coalición estará siempre sobrerrepresentado (Taagepera y Shugart, 1989, p. 88). 
nidas para un nivel pueden terminar convirtiéndose en barreras legales para otro nivel. Así por ejemplo, según el artículo 159 del código electoral vigente a la fecha se establece que para inscribirse los partidos políticos "deben contar con un número de afiliados equivalentes al tres por ciento del total de votos emitidos de la última elección presidencial". Este artículo imposibilita prácticamente la existencia de partidos que únicamente compitan, bien en el nivel departamental, bien en el nivel municipal.

Al hablar de la fórmula electoral se hace referencia al procedimiento matemático para convertir los votos en escaños (presidenciales, parlamentarios o de concejos municipales). Hay dos tipos principales: fórmulas mayoritarias y fórmulas proporcionales. Entre las primeras las más frecuentes son la mayoria simple (plurality), mayoria relativa y mayoría absoluta. Entre las fórmulas proporcionales se encuentran: las fórmulas de cociente electoral común (Hare, Hagenbach-Bischoff, Imperialli y los métodos de reparto de escaños en segunda fase tales como los del Resto Mayor, Resto menor y Media más alta); las fórmulas de divisores comunes (D'hont, Saint-Lagüe, Saint-Lagüe modificada) y la fórmula de proporciones matemáticas (Hare/Niemeyer) $)^{k}$

El hecho que se hable de fórmulas mayoritarias y fórmulas proporcionales no debe llevarnos a identificar mecánicamente a los sistemas mayoritarios con las primeras y a los sistemas proporcionales con las segundas. Este es el sentido por el que Nohlen (1993, pp. 14-18 y 1994, pp. 92-94) ha introducido la distinción entre fórmulas -decisorias- y principios de representación. Mientras que las primeras refieren a la transformación de votos en escaños y están planteadas al nivel de las circunscripciones, las segundas refieren a los objetivos políticos de la representación y, por tanto, se plantean al nivel del resultado general de las elecciones a escala nacional. Esto quiere decir que los principios deberían orientar el diseño del sistema electoral y no tanto las fórmulas o, en ge-

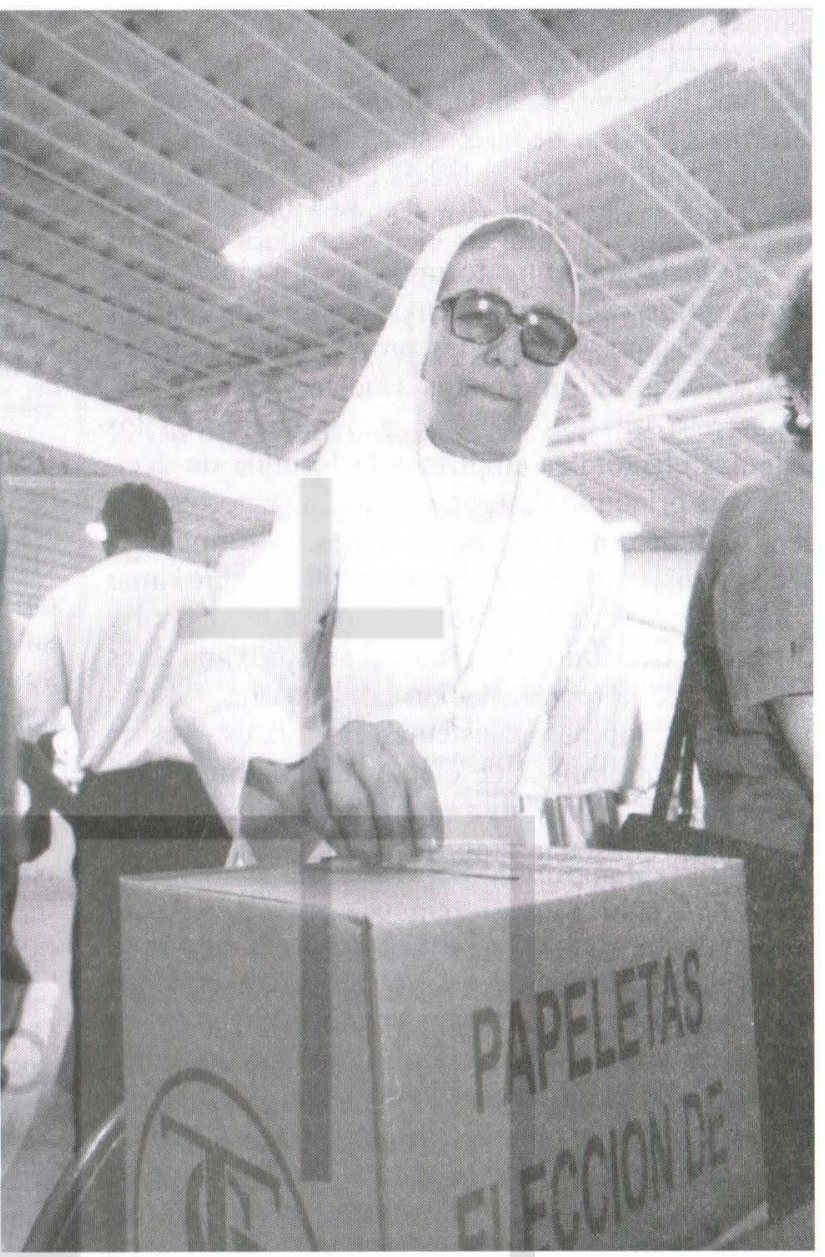

neral, cualquier combinación de sus elementos constituyentes. También quiere decir que una propuesta de reforma electoral debería estar orientada por tales principios y que los diseñadores de tal reforma deberían estar claros al respecto.

Tomando en cuenta los dos tipos de principios mencionados puede distinguirse dos tipos básicos de sistemas electorales: mayoritarios y proporcionales. Cada uno de estos persigue en un objetivo político específico. Los sistemas mayoritarios -sobre todo en regímenes parlamentarios- buscan "fabricar" una mayoría para el partido o coalición de partidos para favorecer la eficacia de la acción gubernamental. El objetivo político de los sistemas proporcionales es más bien reflejar en los órganos

8. Para ver en qué consiste y cómo se hace el reparto de escaños según estas fórmulas puede consultarse: Nohlen (1994, pp. 66-76) y Taagepcra y Shugart (1989, pp. 29-36). 
representativos, con la mayor exactitud posible, las fuerzas sociales y grupos políticos entre la población. En consecuencia, cualquier propuesta de reforma electoral deberia estar claro de cuál es el objetivo político que se busca con el fin de adoptar medidas coherentes con ese objetivo.

La distinción entre fórmulas y principios también permite caer en la cuenta en la posibilidad de diseñar sistemas electorales proporcionales que en la práctica producen efectos asociados con los sistemas mayoritarios. Aunque generalmente en los sistemas electorales empíricos la fórmula de decisión y el principio de representación se corresponden, bajo determinadas condiciones, la fórmula de decisión mayoritaria se aproxima puede aproximar a los objetivos de la representación proporcional y el método decisorio proporcional se aproxima a los objetivos de la representación por mayoría. El anílisis comparado de los sistemas electorales -especialmente en términos de efectos desproporcionales y reductores-constituye en una adecuada metodología para constatar empíricamente estas afirmaciones.

Todos los elementos reseñados hasta aquí operan en la traducción de los votos a escaños. Hace falta considerar los elementos que influyen en el caudal de votos que habría que traducir. Es indudable que en el caso salvadoreño aquí hay que 10mar en consideración al Registro electoral". Constituye el primer filtro para el total de votos que se registrarán en cualquier proceso eleccionario. Quien no está en el Registro no puede votar. Ahora bien, no todas las personas que se encuentran en el Registro electoral pueden votar. Puede darse el caso de personas que, aún estando inscrilas en el Registro, en el momento de la elección ticnen suspendidos, por alguna razón, sus derechos polílicos.

Otro elemento que vale la pena considerar como constituyente de la sistemálica electoral es el padrón electoral. Éste consiste en los listados que el Tribunal Supremo Electoral edita y en los cuales los electores pueden ubicar dónde les toca votar o si hay algún problema con su inscripción en el Registro. Es importante diferenciar entrc Pa- drón y Registro, pues una persona puede estar inscrita en el Registro y sin embargo no aparecer en el Padrón. De hecho, esta es una fuente de anormalidades e irregularidades el día de las votaciones. Algunos potenciales electores se abstienen de votar justamente por las dificultades que surgen en torno a la correcla elaboración y uso del Padrón. Como en El Salvador tenemos una tradición de problemas referentes al Padrón electoral que afecta negativamente a la concurrencia electoral, y por esla vía la dislribución de cuotas de poder, por eso lo estoy considerando como parte del sistema electoral salvadoreño. Por una razón semejante he de incluir entonces al carné electoral. Se sabe que un elector puede estar inscrito en el Registro y sin embargo no estar en posesión de este documento sin el cual es imposible que ejerza su derecho al sufragio. También puede ocurrir que la persona tenga su carné pero que no aparezca en el Padrón o sus datos en éste estén incorrectos. Hay pues diversas situaciones en las que el carné clectoral lermina siendo un faclor decisivo en el caudal de votos registrados en cualquier elección.

La organización del proceso electoral también puede afectar el nivel de concurrencia. Aquí intervienen una serie de procesos y de instancias que su tratamiento analílico requeriría de un mayor espacio que el disponible para este trabajo. Sin embargo, al señalar este elemento como parte de la sistemática electoral quicro dejar constancia de otro ámbito de reforma, aunque no necesariamente en términos jurídicos, y del carácter complejo que ésta manificsta a medida que su alcance y profundidad aumenta".

\subsection{Juicio técnico y juicio político}

De la combinación de todas las posibles alternativas para cada uno de los elementos constitutivos de los sistemas electorales resulta su especifica configuración concreta que condiciona el tipo de resultado electoral que se obtendrá. Cualquier propuesta de reforma electoral en este ámbito debe tomar en cuenta la complejidad del asunto y quicnes la proponen deberían considerar, además, su

9. Scgún el arlículo $19 \mathrm{del} \mathrm{Código} \mathrm{Electoral,} \mathrm{dicho} \mathrm{registro} \mathrm{"estará} \mathrm{constituido} \mathrm{por} \mathrm{todos} \mathrm{los} \mathrm{ciudadanos} \mathrm{Salvado-}$ reños que de acuerdo con la Constitución y las Leyes de la República se encuentren en capacidad de ejercer el sufragio".

10. Que la organización del proceso sea crucial para cl caudal de volos es algo que implícitamente reconoce el Tribunal Supremo Electoral al empeñarse en una re-ingeniería de procesos que lo incluyen y que forman parte de su plan de modernización. 
viabilidad. Cualquier elemento puede ser objeto de modificación. La reforma puede tener distintos grados de profundidad desde una reforma puntual hasta la reforma del Tribunal Supremo Electoral mismo. Estos distintos niveles de reforma ofrecen diversos niveles de viabilidad. Es de esperar que cuanto más profunda se pretenda la reforma, mayores obstáculos surgirán para su realización. En este punto intervienen no solo criterios de legislación secundaria, sino incluso hasta criterios de constitucionalidad.

Como a cada sistema electoral subyace un principio de representación, la reforma no solo dependerá de criterios técnicos - de ingeniería clectoral o de jurisprudencia. También intervienen criterios políticos. Entre los cuales los de mayor peso podrían resultar los intereses partidistas de corto, mediano y largo plazo. Al final de cuentas están en juego las "reglas del juego" y es normal que éstas sean definidas siguiendo la lógica de la disputa por el poder. Aquí reside el profundo sentido político de una reforma electoral. Sería de esperar que los diputados que tienen que aprobar una modificación a las leyes electorales no lo hagan atentando contra los intereses del partido que los ha llevado a la Asamblea legislativa". Para que una situación tal se dé, algún tipo de negociación previa habría ocurrido. Desde este punto de vista, la promulgación e implementación de la Reforma depende no solo de cuán técnicamente elaborada haya sido, sino también de cuán afectados se vean los intereses partidarios en juego ${ }^{12}$. Por esta razón, antes de proponer medidas de reforma "a diestra y siniestra" habría que tener claros y consensuados
- con el mayor margen posible- los objetivos de la Reforma ${ }^{13}$. Éstos orientarán incluso el diagnóstico que haya que realizar. En las páginas que siguen haré un análisis del sistema clectoral salvadoreño enfatizando en aquellos elementos que habría que modificar para mejorar el carácter representativo de los puestos sometidos a clección pública tanto en términos de proporcionalidad como de relación entre representantes y representados.

\section{Un diagnóstico de nuestro sistema electoral}

\subsection{Tres sistemas electorales}

Podría parecer raro afirmar que el sistema electoral salvadoreño en realidad consiste de tres sistcmas electorales. En el país tenemos tres conjuntos de reglas del juego que, aunque se superponen, pueden ser analizados por separado. Cada conjunto de reglas rige para un ámbito preciso de elección: dos de carácter nacional (elecciones presidenciales y legislativas) y otro de carácter local (elecciones de concejos municipales) ${ }^{14}$. Ahora bien, estos tres sistemas no son independientes, sino que interaclúan afectándose mutuamente. Esto facilmente puede sospecharse en el caso de las elecciones de diputados y las de concejos municipales por celebrarse el mismo día -produciéndose un efecto de arrastre del volo de una elección sobre otra. Pero también ocurre aunque cada quince años - según el calendario electoral actual- entre estas dos elecciones y las presidenciales $^{15}$. Por razones analíticas y expositivas me concentraré sucesivamente en cada uno de estos sistemas electorales.

11. Nohlen (1993, p. 41) ha advertido que "los sistemas electorales son productos de compromisos y consensos de las fuerzas políticas vivas de un determinado país".

12. Este razonamiento pone en duda la viabilidad de una reforma clectoral anti-partidos. Si en csic tema se quicre realmente avanzar los intereses de los partidos no hay que olvidar. El punto estaria más bien en cómo discñar una reforma electoral que concilie los intereses partidistas con el interés de mejorar la calidad democrática del régimen. Dicho en términos teóricos, cl asunto está en conciliar intereses parliculares con un interés más general.

13. Respecto al debate necesario antes de llevar a caho una Reforma electoral integral habria que evilar el camino de "presentar primero un sinnúmero de propucstas concretas de reforma (incluso sistemas clectoralcs "idcalcs") por parte de políticos y expertos. Es cl camino más scguro para no alcanzar ninguna reforma. El dchate se cansa en la polémica y la confrontación" (Nohlen, 1993, p. 38).

14. Para ser más precisos deberíamos incluir un cuarto sistema electoral que regula lá clección de los dipulados al Parlamento Centroamericano. Este es otro ámbito de reforma, pero no lo voy a tratar en este trabajo dada la mayor relevancia actual de los otros tres sistemas. Sin embargo, algunas afirmaciones haré en su momento oportuno cuando csté analizando las clecciones de diputados a la Asamblea Lcgislativa.

15. Es lo que habría ocurrido en 1994 donde además se cligicron diputados al Parlamento Centroamericano. 


\subsubsection{Elecciones presidenciales}

El Cuadro 1 resume las características del sistema electoral vigente para las elecciones presi- denciales, según los elementos constituyentes establecidos en el Código Electoral ${ }^{\text {th }}$.

\section{Cuadro 1}

Sistema electoral para las elecciones presidenciales

\begin{tabular}{|c|c|}
\hline Componente & Descripción \\
\hline $\begin{array}{l}\text { M } \\
\text { Distribución de las circunscripciones } \\
\text { Forma de candidatura } \\
\text { Procedimiento de votación }\end{array}$ & $\begin{array}{l}2 \text { (presidente y vicepresidente) } \\
\text { Una sola circunscripción nacional } \\
\text { Lista o planilla, cerrada y bloqueada (Art. 207) } \\
\text { Voto único. }\end{array}$ \\
\hline Barreras & $\begin{array}{l}\text { Umbral de inscripción para el partido: } 3 \% \text { de los votos } \\
\text { emitidos en la últimá elección presidencial (Art. 159) } \\
\text { Umbral para mantener inscripción: (Art. 182) } \\
\text { (a) Partido político: } 3 \% \text { del total de votos válidos en la } \\
\text { elección presidencial. } \\
\text { (b) En coalición: } \\
\text { - símbolo único: } 6 \% \text { (coalición de dos partidos), } 9 \% \\
\text { (coalición de tres partidos) y } 1 \% \text { adicional por } \\
\text { cada partido político superior a tres que integre o } \\
\text { pacte conformar la coalición. } \\
\text { - Símbolo propio: } 3 \% \text { de los votos válidos emitidos. }\end{array}$ \\
\hline Fórmula electoral & Mayoría absoluta y segunda vuelta (Art. 261). \\
\hline
\end{tabular}

$\mathbf{M}=$ Número de representantes a elegir o magnitud de la circunscripción.

Fuente: Elaboración propia, scgún disposiciones del Código Elcctoral.

Dado el carácter mayoritario del sistema de representación en este nivel y la forma presidencialista de gobierno, no tiene sentido hacer un análisis en términos de proporcionalidad para buscar su mejora, según los objetivos planteados en un párrafo anterior. Sin embargo, en términos de la relación entre representantes y representados si hay varias cosas que decir.

Como lo señalé al hacer referencia a los principios de representación, los sistemas mayoritarios tienen como finalidad fabricar mayorías. Este es el sentido de una segunda vuelta electoral cuando por el escaso margen de victoria del partido ganador puede ser fácilmente cuestionada la legitimidad del futuro gobernante. Si los dos partidos con más votos son los que disputan esa segunda vuelta es claro que el partido ganador tendrá más del 50 por ciento de los votos en dicha vuelta. Gozará de una clara mayoría. ¿Qué sucede al respecto en El Salvador?

El Cuadro 2 muestra el margen de victoria del partido ganador en cada una de las cuatro elecciones presidenciales desde 1984. Como puede verse, en ningún caso la victoria ha sido apretada. De hecho, en el último par de elecciones el partido ganador casi ha doblado el caudal de votos de su competidor más cercano. Por otro lado, en dos ocasiones fue necesaria la segunda vuelta donde de todas formas el partido con más votos en la primera vuelta volvió a ganar en la segunda. Se confirma así el efecto de fabricación de mayorías de este componente del sistema electoral. Ahora

16. Me fijaré, primeramente, en los elementos que constituyen los sistemas electorales en sentido restringido o lo que anteriormente scñalé como clementos que inciden cn la traducción de los votos en cscaños. Esto lo harć por scparado para los tres nivcles de clccción. Postcriormente cnfocaré cn los clementos que inciden cn cl caudal de votos que después se traducen en escaños. Esio lo haré de manera conjunta para los tres niveles. 
bien, uno podría preguntarse si, ¿dados los amplios márgenes de victoria en la primera vuelta en las cuatro elecciones, vale la pena la realización de la segunda vuelta?

\section{Cuadro 2 \\ Margen de victoria en las elecciones presidenciales entre 1984 y 1999}

(En porcentajes)

\begin{tabular}{|c|c|c|c|c|}
\hline \multirow[b]{2}{*}{ Año } & \multicolumn{4}{|c|}{ \%Votos \%Votos } \\
\hline & P1 & P2 & M. de V & $\begin{array}{l}\text { Partidos o } \\
\text { coaliciones }\end{array}$ \\
\hline $1984^{*}$ & 43.41 & 29.77 & 13.64 & PDC-ARENA \\
\hline 1989 & 53.82 & 36.03 & 17.79 & ARENA-PDC \\
\hline $1994^{*}$ & 49.11 & 24.99 & 24.12 & $\begin{array}{l}\text { ARENA-FMLN/ } \\
\text { CD/MNR }\end{array}$ \\
\hline 1999 & 51.96 & 29.05 & 22.91 & $\begin{array}{l}\text { ARENA-FMiLN/ } \\
\text { USC }\end{array}$ \\
\hline
\end{tabular}

P1 = primer partido o coalición con más votos.

P2 = scgundo partido o coalición con más votos.

* Sólo primera vuelta.

Fuente: claboración propia con base en resultados oficiales.

Desde el punto de vista de las relaciones entre representantes y representados, la segunda vuelta crea una ficción: el apoyo de una amplia mayoría para el candidato, candidata o partido ganador. Digo que es ficción en la medida que parte de esa mayoría se ha visto obligada por el sistema electoral a dar su voto por un partido que no es su primera opción. La segunda vuelta no garantiza que el electorado que se suma al partido que sacó más votos en la primera vuelta esté votando a su segunda opción partidista -en sentido positivo. Puede estar votando más por el criterio de "el mal menor" -entonces sería una opción en sentido negativo. Sobre todo si se está en presencia de un sistema de partidos polarizado como el salvadoreño. En estas condiciones no sería raro que este electorado "agregado" retire pronto su apoyo al partido ganador una vez en el gobiemo. Se trata de un electorado que en otras condiciones tal vez no habría votado a este partido. El descontento podría ser tal que amenace la estabilidad política o que genere situaciones de ingobernabilidad. Uno de los peores escenarios podría darse si esta situación aparece en los primeros meses o años del gobiemo en tumo y el período presidencial es de cinco o seis años. La rendición de cuentas por la vía electoral aparecería como muy lejana y la paciencia del electorado descontento podría desbordar los canales institucionales. Otro resultado podría ser el de un mayor alejamiento de la ciudadanía respecto a las instituciones políticas. Ninguno de estos dos escenarios es deseable para la consolidación de un régimen democrático en El Salvador.

Por otra parte, ¿qué costos financieros tiene celebrar una segunda vuelta electoral que reafirme el triunfo del partido ganador en primera vuelta? El Cuadro 3 muestra lo que en materia de fórmula electoral está establecido en los países vecinos de la región centroamericana. Honduras, Nicaragua y Costa Rica no han adoptado la mayoría absoluta, pero tampoco tienen el mismo criterio de mayoría simple o relativa.

Cuadro 3

Elección presidencial en Centroamérica

\begin{tabular}{lllc}
\hline País & Año & Mayoría exigida & Ballotage" \\
\hline Guatemala & 1999 & Absoluta & Sí \\
El Salvador & 1999 & Absoluta & Sí \\
Honduras & 1997 & Simple & No \\
Nicaragua & 1996 & Al menos el 45\% votos válidos & Sí \\
Costa Rica & 1998 & Más del 40\% votos válidos & Sí \\
\hline
\end{tabular}

- Segunda vuelta entre las dos candidaturas con mayor número de votos.

Fuente: Elaboración propia basada en las respectivas Leyes Electorales.

\subsubsection{Elecciones legislativas ${ }^{17}$}

El Cuadro 4 resume las características del sistema electoral vigente para las elecciones de dipu- tados a la Asamblea legislativa según lo regulado por el Código Electoral. El análisis que sigue lo haré tomando en cuenta los criterios de proporcio-

17. Otros análisis sobre el sistema electoral para las elecciones legislativas puede verse en Artiga-González (1997) y (1996). 
nalidad y de relaciones entre representantes y representados. Tratándose de un sistema basado en el principio de representación proporcional, su diseño —es decir, la combinación de sus elementos constituyentes - debería apuntar en esa dirección o sea favorecer el reparto proporcional de los escaños legislativos.

La proporcionalidad del sistema pone en relación votos y escaños. No se trata de un sistema en el que ciertos sectores o grupos sociales -étnicos, etarios, religiosos, de género, de clase, etc.- de- berían estar representados proporcionalmente en la Asamblea Legislativa. Si acaso, lo que estaría representado proporcionalmente sería la distribución de preferencias partidistas. Esto es importante señalarlo especialmente respecto de los grupos de género. Si bien hay intentos en algunos partidos políticos de establecer cuotas de representación a la hora de seleccionar candidatos según género, lejos estamos de tener una Asamblea Legislativa compuesta por una mayoría femenina tal como ocurre entre la ciudadanía a quien la Asamblea representa.

\section{Cuadro 4}

Sistema electoral para la elección de diputados

\begin{tabular}{|c|c|}
\hline Componente & Descripción \\
\hline $\begin{array}{l}\text { M } \\
\text { Distribución de las circunscripciones }\end{array}$ & $\begin{array}{l}84 \text { diputados (Art. 12) } \\
15 \text { circunscripciones plurinominales distribuidas así: } 1 \text { de } \\
16 \text { escaños, } 1 \text { de } 6,2 \text { de } 5,2 \text { de } 4,8 \text { de } 3 \text { y } 1 \text { de } 20 \text {. }\end{array}$ \\
\hline $\begin{array}{l}\text { Forma de candidatura } \\
\text { Procedimiento de votación }\end{array}$ & $\begin{array}{l}\text { Lista o planilla cerrada y bloqueada } \\
\text { Voto único }\end{array}$ \\
\hline $\begin{array}{l}\text { Barreras } \\
\text { Fórmula electoral }\end{array}$ & $\begin{array}{l}\text { Umbral de inscripción para el partido: } 3 \% \text { de los volos } \\
\text { emitidos en la última elección presidencial (Art. 159) } \\
\text { Umbral para mantener inscripción: (Art. 182) } \\
\text { (c) Partido político: } 3 \% \text { del total de votos válidos en la } \\
\text { elección legislativa. } \\
\text { (d) En coalición: } \\
- \text { símbolo único: } 6 \% \text { (coalición de dos partidos), } \\
9 \% \text { (coalición de tres partidos) y } 1 \% \text { adicional por } \\
\text { cada partido político superior a tres que integre o } \\
\text { pacte conformar la coalición. } \\
\text { - Símbolo propio: } 3 \% \text { de los votos válidos emitidos. } \\
\text { Cociente electoral y residuo mayor (Art. 262). }\end{array}$ \\
\hline
\end{tabular}

M = Magnilud o lamaño de la circunscripción.

Fuente: Elaboración propia según disposiciones del Código Electoral.

Existen varias formas de aproximación al análisis de la proporcionalidad. En todas subyace el criterio que establece que a cada partido debería corresponder un número de diputados, según el caudal de votos que ha obtenido en la elección. En términos porcentuales, lo ideal sería que hubiese una coincidencia entre porcentaje de votos y porcentaje de escaños ${ }^{1 k}$. Sin embargo, la situación normal es encontrar "desviaciones" de esta regla. Estas desviaciones constituyen los llamados efectos desproporcionales. Cuanto mayores son las desviaciones mayor es la desproporcionalidad que

18. Matemáticamente esta situación podría representarse gríficamente mediante una línca recta a 45 grados, es decir, aquella cuya pendiente cs igual a I. Dicho de otra forma, el cociente de la proporción de volos cnirc la proporción de escaños es igual a 1. 
produce el sistema. Es de esperar que los sistemas mayoritarios sean más desproporcionales que los sistemas proporcionales. Pero entre éstos también hay diversos grados de proporcionalidad o desproporcionalidad. ¿Cómo podemos medir la proporcionalidad de nuestro sistema?

Uno de los índices de proporcionalidad que goza de amplia aceptación entre los politólogos es el índice de $R_{o s e^{14}}$. El Cuadro 5 muestra los valores que adopta este índice en las elecciones legislativas del período 1982 2000. Salvo para el año 1985 , el índice de Rose supera los 90 puntos porcentuales. El promedio para todo el período es de 92.7. ¿Es alta o baja esta proporcionalidad? Creo que observar qué ocurre en los países vecinos puede arrojar alguna luz al respecto. El Cuadro 6 recoge los valores del índice de Rose para los países centroamericanos en el período 1980-2000). Puede notarse claramente que El Salvador tiene uno de los sistemas menos proporcionales del área.

¿Favorece a algún partido en particular este diseño instilucional? En general puede decirse que hay una tendencia a favorecer a los parlidos más grandes en detrimento de los partidos pequeños. Esta afirmación puede verificarse empíricamente a través del análisis de la desviación electoral ${ }^{\prime \prime}$. Por otra parte, también puede comprobarse que existe una cierta proporción de votos que garantiza, casi al cien por ciento, que la proporción de escaños será mayor que aquélla. Dicha proporción de votos constituye un punto más allá del cual los partidos reciben un plus de representación ${ }^{21}$. Sin que constituya una ley, empiricamente ha resultado que el tercer partido con más volos ha tendido a recibir el mayor plus. Estas situaciones planteadas quedan de manifiesto en el Cuadro 7 y en la Gráfica 2. Para la elaboración de esta última he tomado en cuenta todos, los pares de votos y escaños registrados en el período $1982-2000$.

19. Se calcula mediante la fórmula $100-1 / 2 \Sigma \mid V i$ - Si $\mid$. Jonde Vi y Si son los porcentajes de volos y escaños del "i-ésimo" partido. El máximo valor es $1(\%)$, que expresaría una siluación de perfecla proporcionalidad donde no exislirían diferencia entre la proporción de votos y cscaños.

20. Un índice de desviación electoral pucde calcularse por la fórmula: $\mathrm{DE}=(\mathrm{Si} / \mathrm{Vi}) \times 100-100$. Valores positivos de cste índice significan una sobrerrepresentación (cl partido recibe una proporción de cscaños mayor que la de votos) y valores negativos de este índice significan una subrrepresentación (el partido recibe una proporción de escaños menor que la de volos).

21. Este punto se conoce en la literatura politológica como break even point. 
Cuadro 7

Desviación electoral producida por el sistema electoral

salvadoreño en elecciones legislativas (1982-2000)

\begin{tabular}{|c|c|c|c|c|c|c|c|}
\hline Partido & 1982 & 1985 & 1988 & 1991 & 1994 & 1997 & 2000 \\
\hline ARENA & 7.46 & -27.27 & 4.17 & 4.74 & 3.11 & -5.93 & -4.17 \\
\hline PDC & -0.25 & 5.16 & 8.81 & 10.71 & 19.55 & 27.38 & -16.67 \\
\hline PCN & 21.35 & 138.10 & 36.05 & 18.89 & -22.58 & 50.57 & 88.64 \\
\hline PPS & -41.38 & & & & & & \\
\hline$A D$ & -55.41 & -54.05 & & & & & \\
\hline PAISA & & -54.05 & & & & & \\
\hline $\mathrm{CD}$ & & & & -21.49 & -72.73 & -31.42 & \\
\hline MAC & & & & -62.50 & & & \\
\hline UDN & & & & -55.56 & & & \\
\hline FMLN & & & & & 16.82 & -2.73 & 4.83 \\
\hline MU & & & & & -52.00 & -47.83 & \\
\hline PD & & & & & & 0.00 & \\
\hline PLD & & & & & & -25.00 & \\
\hline PRSC & & & & & & 0.00 & \\
\hline $\mathrm{CDU}$ & & & & & & & -33.33 \\
\hline PAN & & & & & & & -35.14 \\
\hline
\end{tabular}

Fuente: Elaboración propia.

El Cuadro 7 evidencia cómo el PCN ha sido el partido que en todo el período se ha visto mayormente beneficiado por nuestro sistema electoral. Sus valores de desviación electoral son todos positivos, excepto en 1994, y además se trata de unos valores bastante altos. 1985 y 2000 fueron los años en los que mayor sobrerrepresentación logró. En 1985 gracias a una política de alianza con el partido ARENA y en 2000 gracias a la distribución de las magnitudes como lo he mostrado en olro trabajo ${ }^{22}$. Ahora bien, ¿qué representa el PCN en términos sistémicos? El PCN fue el tercer parlido con más votos en 1982, 1985, 1988, 1997 y 2000. En 1994, el tercer partido más volado fue el PDC y también es el partido con mayor sobrerepresentación. En 1991, el tercer partido fue CD, pero fue el PCN el tercer partido con más escaños. Pareciera aquí haber una regla: existe una tendencia a que la tercera fuerza política electoral reciba el mayor premio en el reparto de los escaños.

Por otra parte, los valores negativos de la desviación electoral generalmente son mayores para los casos de los partidos pequeños. Esto es especialmente notable si se contrasta con los valores negativos que resultan para los casos de los partidos grandes ARENA y FMLN. Esta es una evidencia más de cómo nuestro sistema electoral favorece directamente a los tres primeros partidos en detrimento del resto. Se trata de una llave institucional a favor de los grandes partidos.

Por su parte, la Gráfica 2 describe gráficamente el comportamicnto del sistema electoral a la hora del reparto de los escaños. La línea curva es una aproximación al comportamiento real de la relación entre escaños y votos. La distribución ideal de escaños respecto de los votos está representada por la línea horizontal igual a 1.000 para la cual a un determinado porcentaje de votos corresponde igual porcentaje de escaños. El punto de intersección de ambas líneas es de interés para el análisis. Puede verse como salvo contadas excepciones (5 de 23 casos) si un partido obtiene más del 9 por ciento de votos recibirá un plus de representación. A partir de este punto, la línea curva siempre está por encima del valor 1 para el cociente escaños/ volos. El plus de representación ha sido mayor cuando el porcentaje de votos ha oscilado entre 9 y $20^{23}$.

22. Véase Artiga-González (2000).

23. La concentración de puntos en el gráfico entre 0 y 9 por ciento de los votos corresponde a los partidos pequeños, cuya relación escaños/votos no supera cl valor ideal de 1. 
¿Dónde están las fuentes de eslos eleclos desproporcionales del sistema salvadoreño' Como lo he señalado en diferentes ocasiones, dicha fuente hay que buscarla en la distribución de las circunscripciones y no en la fórmula electoral. Para sustentar esta afirmación he elaborado el Cuadro 8 en el cual hago una simulación acerca de la proporcionalidad que se habría obtenido, con los datos electorales de 2000 , si se hubiese cambiado la fórmula electoral, la distribución de las circunscripciones o ambas. Como puede apreciarse a Iravés de los valores que asume el índice de Rose para las distintas alternativas la mayor proporcionalidad se tiene cuando se modifica la distribución de las circunscripciones. La discusión se trasladaría entonces a la mejor alternativa, de distribución de los escaños. Este es el momento donde entra en juego el tema de la relación entre representantes y representados. Ya no se trata únicamente de la búsqueda de una mayor proporcionalidad en función de las preferencias expresadas en votos. Aparece también el problema de a quiénes deben representar los diputados electos.

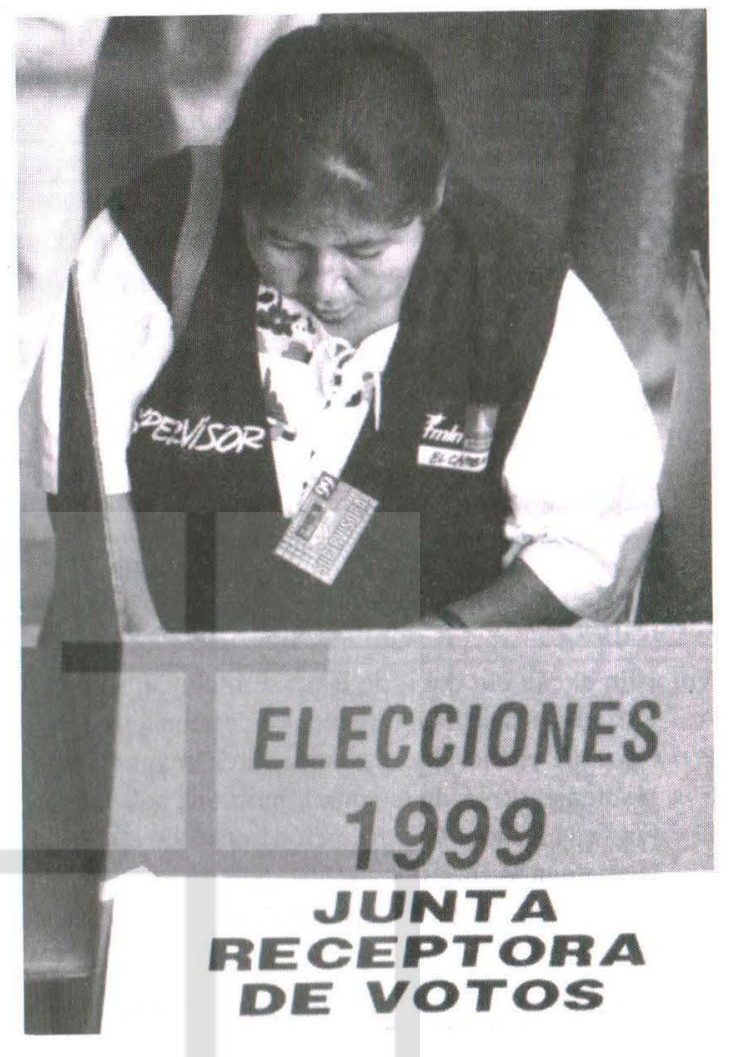

Gráfica 2

Buscando el punto del plus de representación (1982-2000)

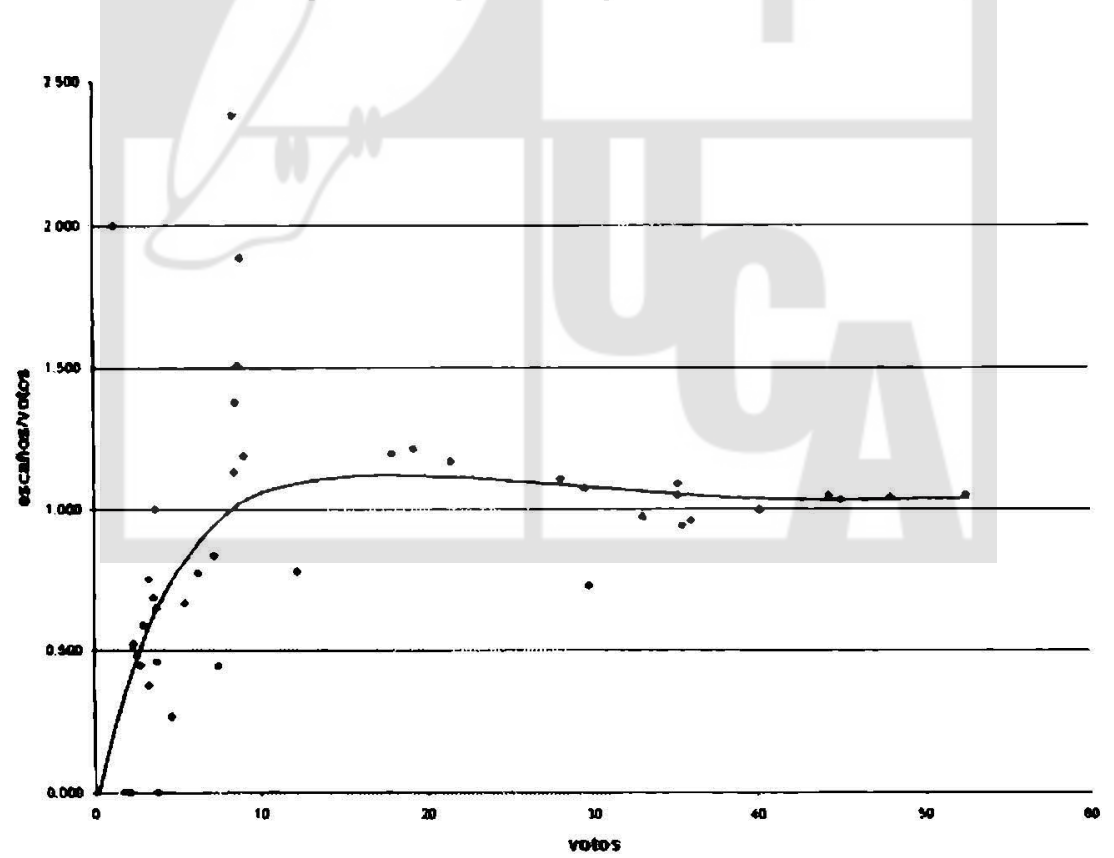


Cuadro 8

Proporcionalidad según diversos diseños de sistema electoral

\begin{tabular}{lrrrrrr}
\hline & & \multicolumn{7}{c}{ \% Escaños } \\
\cline { 2 - 6 } Partido & \% Votos & \multicolumn{1}{c}{$\mathrm{A}$} & \multicolumn{1}{c}{$\mathrm{B}$} & $\mathrm{C}$ & \multicolumn{1}{c}{$\mathrm{D}$} & \multicolumn{1}{c}{$\mathrm{E}$} \\
\hline ARENA & 36.04 & 34.52 & 29.76 & 35.71 & 47.62 & 35.72 \\
CDU & 5.38 & 3.57 & 4.76 & 5.95 & 2.38 & 5.96 \\
FMLN & 35.22 & 36.90 & 26.19 & 35.71 & 41.67 & 34.52 \\
PAN & 3.71 & 2.39 & 0.00 & 3.57 & 0.00 & 4.76 \\
PCN & 8.82 & 16.67 & 1.19 & 8.34 & 5.95 & 9.52 \\
PDC & 7.19 & 5.95 & 2.38 & 7.15 & 2.38 & 8.33 \\
PLD & 1.29 & 0.00 & 13.10 & 1.19 & 0.00 & 1.19 \\
PPL & 0.42 & 0.00 & 16.67 & 0.00 & 0.00 & 0.00 \\
USC & 1.93 & 0.00 & 5.95 & 2.38 & 0.00 & 0.00 \\
\hline Totales & 100.00 & 100.00 & 100.00 & 100.00 & 100.00 & 100.00 \\
l. de Rose & & 92.29 & 69.78 & 98.70 & 85.65 & 97.71 \\
\hline
\end{tabular}

Nota: En el cálculo del I. de Rose se incluyen sólo los partidos que logran escaños.

$\mathrm{A}=$ Fórmula y distribución actual de circunscripciones.

$\mathrm{B}=$ Cociente electoral y restos menores, manteniendo distribución actual.

C = Manteniendo fórmula actual, pero una sola circunscripción.

$\mathrm{D}=$ Fórmula $\mathrm{D}$ 'hont y distribución actual de circunscripciones.

$\mathrm{E}=$ Manteniendo fórmula y realizando distribución en cinco circunscripciones

(occidental, central, paracentral, oriental y nacional).

El Cuadro 9 recoge lo normado por el Código Electoral para la distribución de los diputados en
15 circunscripciones (14 departamentales y 1 nacional). Aunque puede sospecharse que esta distri-

\section{Cuadro 9}

Distribución de diputados por departamento

\begin{tabular}{lrrr}
\hline Departamento & Población" & M $^{r}$ & Razón de representación \\
\hline San Salvador & $1,985,294$ & 16 & 124,080 \\
Santa Ana & 551,259 & 6 & 91,876 \\
San Miguel & 480,276 & 5 & 96,055 \\
La Libertad & 682,092 & 5 & 136,418 \\
Usulután & 338,332 & 4 & 84,583 \\
Sonsonate & 450,116 & 4 & 112,529 \\
La Unión & 289,021 & 3 & 96,340 \\
La Paz & 292,887 & 3 & 97,629 \\
Chalatenango & 196,583 & 3 & 65,527 \\
Cuscatlán & 202,951 & 3 & 67,650 \\
Ahuachapán & 319,780 & 3 & 106,593 \\
Morazán & 173,499 & 3 & 57,833 \\
San Vicente & 161,105 & 3 & 53,701 \\
Cabañas & 152,842 & 3 & 50,947 \\
\hline Totales & $6,276,037$ & 64 & 98,063 \\
\hline
\end{tabular}

"Proyección para el año 2000.

' Magnitud o tamaño de la circunscripción (diputados asignados).

c Población/diputados.

Fucnte: Elaboración propia sobrc datos de la DIGYESTYC (1996) y el TSE (2000). 
bución buscaba estar acorde con la distribución de la población a lo largo y ancho del territorio nacional, no existe una definición explícita de esa intención. En la práctica ocurre que no existe tal proporcionalidad. La razón de representación, mostrada también en el Cuadro 9, muestra las desigualdades que genera la distribución actual de los escaños legislativos, según departamentos. Es notorio lo que sucede entre los casos extremos. Por ejemplo, San Salvador, La Libertad, Sonsonate y Ahuachapán tienen asignados un diputado por cada más de 100 mil habitantes, mientras que Cabañas y San Vicente lo tienen por cerca de cada 50 mil. En términos comparativos, estos últimos dos departamentos estarían sobrerrepresentados. Otras distorsiones pueden verse comparando departamentos como Santa Ana y La Libertad. Éste tiene asignados menos diputados, a pesar de tener una mayor población que el primero ${ }^{24}$. Otra disparidad se nota al comparar los casos de Usulután y Sonsonate, donde, a pesar de existir una diferencia mayor que los 100 mil habilantes, ambos departamentos tienen asignado igual número de escaños.

Este malapportionment de dipulados lambién se manifiesta cuando se trabaja con los cocientes electorales correspondientes a cada circunscripción con el agravante que entonces se viola el principio de igualdad del voto. Esto hace que los diputados tengan diferentes "precios", scgún departamentos. Dicho de olra forma, hay circunscripciones donde los diputados son más caros y circunscripciones donde ganar un escaño es más barato. El Cuadro 10 muestra los distintos "precios" de los diputados en las elecciones del $200\left(0^{25}\right.$. Los departamentos donde el voto vale más son San Vicente y Cabañas. En Sonsonate y La Paz se necesita el doble de votos que en los mencionados departamentos para obtener un dipulado. Y el volo de Cabañas casi vale el triple que el volo en La Libertad. En estas condiciones lejos se está del principio de igualdad del voto.

Ciertamente se trata de un problema de difícil solución, puesto que el "precio" del diputado o el "valor" del volo depende de la cantidad de votos válidos emitidos en cada circunscripción. En la medida que la cantidad de diputados por circunscripción está fijada por ley, el malapportionment depende de la cantidad de votos. La única manera de eliminarlo sería fijando el cociente electoral pero entonces lo variable de elección a elección sería el tamaño de las circunscripciones y, por tanto, el tamaño de la Asamblea Legislativa. Ésta ya no tendría 84 diputados, sino un número variable en función de la cantidad de votos válidos emitidos.

\begin{tabular}{|c|c|c|}
\hline \multicolumn{3}{|c|}{$\begin{array}{c}\text { Cuadro } 10 \\
\text { Cociente electoral, según circunscripción } \\
\text { en elecciones del } 2000\end{array}$} \\
\hline Departamento & $\begin{array}{c}\text { Votos } \\
\text { válidos }\end{array}$ & $\begin{array}{l}\text { Cociente } \\
\text { electoral }\end{array}$ \\
\hline San Salvador & 363,846 & 22,740 \\
\hline Santa Ana & 101,198 & 16,866 \\
\hline San Miguel & 84,830 & 16,966 \\
\hline La Libertad & 132,191 & 26,438 \\
\hline Usulután & 71,297 & 17,824 \\
\hline Sonsonate & 91,377 & 22,844 \\
\hline La Unión & 43,402 & 14,467 \\
\hline La Paz & 66,196 & 22,065 \\
\hline Chalatenango & 50,882 & 16,960 \\
\hline Cuscatlán & $44,960)$ & 14,986 \\
\hline Ahuachapán & 58,223 & 19,407 \\
\hline Morazán & 39,817 & 13,272 \\
\hline San Vicente & 32,804 & 10,934 \\
\hline Cabañas & 29.246 & 9,748 \\
\hline Totales & $1,210,269$ & 18,910 \\
\hline
\end{tabular}

Fuente: Elaboración propia.

En un párrafo anterior sugería que el problema de la representación en la Asamblea Legislativa no era solo una cuestión cuantitativa, de proporcionalidad. También es un problema cualitativo. ¿A quién representan Ios diputados? ¿A Ios partidos? ¿A los electores? ¿Qué mecanismos tienen estos últimos para controlar la acción de los primeros? ¿Cómo influye en la relación representantes/representados el sistema electoral? El análisis de la forma de la candidatura nos permite una primera aproximación al asunto para tratar de responder lodas estas preguntas. En este sentido, recordemos

24. La Liberlad lienc 130,833 habitantes más que Santa Ana. Ésta ticne 70,983 habilantes y un diputado más que San Miguel. Por pura ley transitiva, La Libertad deberia tener, por lo menos, un diputado más que Santa Ana.

25. El correlato del "precio" de los diputados es el "valor" del voto. Hay circunscripciones donde el voto vale más y circunscripciones donde el voto vale menos. Allí donde vale más se necesilan menos votos para obıener un dipulado. Allí donde valen menos se necesitan más votos para alcanzar un escaño. 
que la elección de diputados se lleva a cabo mediante una lista cerrada y bloqueada. Dado que hasta la fecha, en El Salvador, la norma general para seleccionar a los candidatos dentro de los partidos no pasa por elecciones primarias, este mecanismo le da un mayor poder de control a las cúpulas partidistas. Éstas son las que nombran a los candidatos y después los ofrecen al electorado. A éste no le queda más que dar un si, un no, o abstenerse frente a la propuesta partidista. En estas condiciones una cúpula partidista puede imponer como candidato a diputado por determinado departamento a una persona que ni siquiera viva en ese departamento.

Por otra parte, el control que ejerce la cúpula partidista en la nominación de candidatos tiene repercusiones en el comportamiento de los diputados durante la legislatura. En estas condiciones, no es raro encontrarse con partidos muy disciplinados, cuyos diputados suelen votar en bloque según las directrices de los líderes de fracción. Quien se sale de la línea corre el riesgo de ser sancionado por el partido. Incluso puede llegarse a su expulsión. En el mejor de los casos, el diputado que se niega a seguir la línea partidista termina convirtiéndose en diputado independiente. La cuestión del control ciudadano sobre su comportamiento ahora se vuelve más difícil por cuanto en estas condiciones tal diputado sabe que sus días en la Asamblea están contados. No será reelegido para un nuevo período al haber perdido el nexo con el partido. No tiene nada más que perder. Ahora puede dedicarse a "pasarla suave" y disfrutar de su "jugoso salario". Estando vinculado al partido, éste le controlaba ${ }^{2 h}$.

La rendición de cuentas de los diputados a quienes votaron por ellos también pasa por el disenoo de las circunscripciones. En El Salvador se ha optado por seguir la división territorial-administrativa y 14 de las 15 circunscripciones son departamentales. Que se haya optado por este diseño no implica necesariamente que los diputados representan los intereses de sus votantes dentro de las circunscripciones donde fueron elegidos. Para que esto así fuera ni siquiera están dadas las condiciones aritméticas. ¿Qué puede hacer un diputado de La Unión en el seno de la Asamblea para hacer valer los intereses de los unionenses que le votaron? Es claro que los intereses de los habitantes del departamento de San Salvador estarían mejor resguardados que los de cualquier otro departamento porque cuentan con 16 volos. Desde este punto de vista tenemos un diseño institucional para nuestro sistema electoral que favorece la centralización de las decisiones legislativas. Por supuesto que estoy argumentando bajo el supuesto de que los diputados obedecen a los intereses de los votantes de la circunscripción en que son elegidos. Pero, ¿son así las cosas en la práctica? No es difícil responder negalivamente a esta pregun$\operatorname{ta}^{27}$. ¿Qué decir de los diputados de la circunscripción nacional? Es cierto que la inclusión de esta circunscripción favorece la proporcionalidad del sistema pero, ia quiénes representan sus diputados? ¿Qué control ejercen los electores si incluso para elegirlos no tienen opción? Digo esto porque la circunscripción nacional es elegida partiendo del total de votos nacionales. Votando por los diputados departamentales estamos votando, independientemente que lo querramos o no, por los diputados nacionales.

Aunque lo trataré más adelante, quiero mencionarlo también en este momento. Dado que las elecciones legislativas son simultáneas con las elecciones municipales, se produce un efecto de arrastre de una elección hacia la otra. Esto quiere decir que existe una tendencia entre el electorado a dar el voto por el mismo partido en ambas elecciones. Si bien es cierto que hay electores que, individualmente, pueden dar un volo cruzado marcando la bandera de distintos partidos en cada uno de los tipos de elección, en términos agregados la

26. Se pucde discutir si este control partidista es adccuado o no para el bucn funcionamicnto de la Asamblea Legislativa. Algunos analistas podrian argumentar que es mejor que los diputados voten en las plenarias siguiendo su conciencia antes que la línca partidista. A mí me parece que el quid de la cucstión está más bicn $\mathrm{cn}$ cómo le controlan aquellos que han votado para que él o clla les represente en los debates parlamentarios.

27. Al momento de redactar este trabajo pasamos en El Salvador un estado de emergencia por el terremoto del 13 de encro. Que los diputados viven alcjados de lo que ocurre en sus circunscripciones queda de manifiesto por su poca o nula presencia en los lugares afectados. Una inicialiva del CDU para que los dipulados donaran un día de salario para los damnificados no prosperó y fue archivada. ¿No habría sido un buen gesio hacia aquellos que con su voto les favorecen para que pucdan gozar del salario que como diputados reciben? 
tendencia es hacia la homogeneidad del voto, es decir, al voto por el mismo partido ${ }^{28}$. Como aquí rozamos ya el ámbito de la elección municipal, creo que es el momento de pasar al análisis de su sistema electoral. Sin embargo, para finalizar el análisis del sistema electoral legislativo, quiero traer a cuenta el hecho que el Código Electoral no permite la existencia de partidos de carácter departamental o regional. Por ejemplo, no existe un partido que sólo compita en San Miguel o sólo en la zona oriental. Esto sucede no por prohibición normativa, sino por el efecto práctico de la barrera legal para la inscripción de un partido político que tiene que contar, como mínimo, con un número de afiliados equivalente al tres por ciento del total de votos emitidos en la última elección presidencial (Art. 159). Si el total de votos válidos en 1999 fue de $1,182,248$, un partido departamental tendría que registrar 35,467 afiliados al momento de su inscripción en el TSE. En la práctica se trata de un umbral imposible de superar en muchos de los departamentos para casi todos los partidos, pues su total de votos departamentales suele estar por debajo de este límite.

\subsubsection{Elecciones municipales}

El Cuadro 11 resume las características del sistema electoral vigente para las elecciones de concejos municipales, según lo establecido en el Código Electoral. Se trata de un sistema mayoritario cuyo proceso electoral es simultáneo al de las elecciones para dipulados. Esto es importante hacerlo notar, por cuanto significa que interactúan dos sistemas con principios de representación opueslos.

\section{Cuadro 11}

Sistema electoral para las elecciones de concejos municipales

\begin{tabular}{l|l}
\hline Componente & Descripción \\
\hline $\mathbf{M}$ & $\begin{array}{l}\text { En cada municipio se elige un alcalde, un síndico y un } \\
\text { número de regidores que varía según el tamaño } \\
\text { poblacional del municipio y cuatro miembros suplentes } \\
\text { (Art. 13). }\end{array}$ \\
$\begin{array}{l}\text { Distribución de las circunscripciones } \\
\text { Lista o planilla cerrada y bloqueada } \\
\text { Forma de candidatura }\end{array}$ & $\begin{array}{l}\text { Voto único } \\
\text { Procedimiento de votación }\end{array}$ \\
\hline Barreras & $\begin{array}{l}\text { No se establece explícitamente. Sin embargo vale el um- } \\
\text { bral de inscripción del 3\% de los votos emitidos en la } \\
\text { última elección presidencial (Art. 159) } \\
\text { Mayoría simple (Art. 264) }\end{array}$ \\
\hline
\end{tabular}

$M=$ Magnitud o tamaño de la circunscripción.

Fuente: Elaboración propia según disposiciones del Código Elcctoral.

Como puede observarse, el número de representantes que se eligen en cada municipio varía de acuerdo con el tamaño de la población ${ }^{24}$. Cosa diferente a lo establecido para el caso de los diputados que tiene asignado cada departamento. Ahora bien, dado que el principio de representación es mayoritario no se presenta el problema de viola- ción del principio de la igualdad del voto. Pero es que, además, los miembros del Concejo Municipal solo ejercen el poder político en la circunscripción que les confiere el voto. Esto impide que haya concejales más "baratos" en unas zonas respecto de otras.

28. Un análisis más en profundidad sobre está temática puede consultarse en Artiga-González (20)0)b).

29. En csto cl Código es muy cspecífico, pucsio que cstablcce explícitamentc quc: "En cada Municipio, sc clegirá un Concejo Municipal compuesto por un Alcalde, un Síndico, dos Regidores y cuatro Miembros Suplentes, para sustituir indistintamente a cualquier propietario. Además en las poblaciones con más de cinco mil habitantes, se clegirán Rcgidores en la siguiente proporción: 
Por otra parte, por tratarse de una candidatura de lista cerrada y bloqueada como en el caso de la asamblea legislativa, por el mismo principio de representación mayoritaria, el partido que obtiene más votos logra todos los escaños en disputa. Es claro que con este sistema se busca favorecer la acción de gobierno antes que la representatividad del gobiemo municipal. La lista cerrada y bloqueada combinada con la fórmula de mayoría simple permite la composición "monocolor" del gobierno local ${ }^{\text {*a. }}$. Así se bloquea la oposición de olras fracciones partidistas dentro de ese gobierno durante su gestión. Sin embargo, es posible que el partido que controla el gobierno municipal sea un partido que no goza de una mayoría absoluta de las preferencias de los electores en su circunscripción. Su mayoría puede ser tan relativa que solo implica que se trata del partido con más votos. Contrastado con la suma de votos del resto de partidos, el caudal de votos del partido ganador puede ser minoritario. En este sentido, puede hablarse de gobiernos minoritarios. Resulta que en El Salvador esta situación no es infrecuente. Si consideramos los resultados electorales de 1994, 1997 y 2000 podemos ver que este escenario es el más frecuente en nuestro país.

El Cuadro 12 muestra la evolución de la distribución de gobiernos municipales minoritarios según los diferentes departamentos del país. Puede verse cómo se registra una tendencia al incremento de gobiernos minoritarios pasando de 167 a 195 entre 1994 y 2000 . Esto podría significar que, en general, el voto municipal liende a reparlirse entre las distintas opciones partidistas cada vez más. Digo que esto podría ser porque no necesariamente la causa reside en la diversificación del voto. También podría deberse a la disminución paulatina de los apoyos a los partidos mayoritarios en cada municipio sin que ese voto vaya a otro partido. Se trataría entonces de una desmovilización de electores de un partido que convierte a los gobiernos de dicho partido en gobiernos minorilarios ( $\mathrm{si}$ es que todavía conservan el gobierno). Indepen- dientemente de cuál sea la causa del incremento de gobiernos minoritarios, en términos de diseño del sistema electoral interesa preguntarse si este es el mejor diseño desde el punto de vista de la relación entre gobernantes y gobernados.

Si observamos lo que ocurre en cada uno de los departamentos nos damos cuenta que Ahuachapán es el departamento donde casi el cien por ciento de los municipios ha tenido gobiemos minoritarios, mientras que La Unión muestra una tendencia hacia la disminución de éstos. En el 2000 , el cincuenta por ciento de los municipios de este departamento tenía gobiernos minoritarios. Otro caso interesante es el de Sonsonate, donde 14 de 16 municipios resultaron con gobiemos minoritarios tanto en 1997 como en el 2000.

Por otra parte, la fórmula mayoritaria vuelve inútiles los votos de quienes optaron por los partidos diferentes al de mayor caudal electoral. Es cierto que si los partidos pasan más allá del 50 por ciento de votos gozan de una amplia legitimidad. Pero ya hemos visto que casi solo una cuarta parte de los municipios cae en esta clase. Las otras tres cuartas partes (al menos para 1997 y 2000) son gobiernos municipales minorilarios. Aquí ya no solo es inúlil el volo, sino que las diferencias entre el partido ganador y el más cercano competidor pueden ser pequeñas, no importando a la hora del reparto de escaños.

Si volvemos al Cuadro 11 nos daremos cuenta que la candidatura es de lista cerrada y bloqueada. Sin embargo, los partidos contendientes la manejan no tanto como una lista, sino como una candidatura unipersonal. Es decir, los partidos suelen plantear su oferta en términos de la candidatura del alcalde. Como si solo se tratara de la elección del alcalde y no de todo el concejo municipal como realmente es. Esta forma de proceder de los partidos fomenta la personalización de la política a nivel municipal. Se reproduce así una especie de presidencialismo chiquito o "presidencialismito" donde pareciera que todo pende de la capacidad

Cuatro Concejales o Regidores en los Municipios que tengan más de diez mil hasta veinte mil habitantes:

Scis Conccjales o Regidores en los Municipios que tengan más de veinte mil hasta cincucnta mil habilantes;

Ocho Concejales o Regidores en los Municipios que tengan más de cincuenta mil hasta cien mil habitantes;

Diez Concejales o Regidores en los Municipios que lengan más de cien mil habilantes.

El Tribunal eslablecerá el número de Concejales o Regidores en cada municipio, en base al último censo de población oficial, y lo notificará a los Partidos Polílicos y Coaliciones inscritos, con cuarenta y cinco días de anticipación a la convocatoria de elecciones" (Art. 1.3).

30. Utilizo aquí cl término "local" como sinónimo de "municipal". 


\section{Cuadro 12 \\ Distribución de gobiernos municipales minoritarios, según departamento (1997-2000)}

\begin{tabular}{|c|c|c|c|c|c|c|c|}
\hline \multirow{3}{*}{ Departamento } & \multirow{3}{*}{$\begin{array}{l}\text { Total de } \\
\text { municipios }\end{array}$} & \multicolumn{6}{|c|}{ Municipios con gobierno minoritario } \\
\hline & & \multicolumn{2}{|c|}{1994} & \multicolumn{2}{|c|}{1997} & \multicolumn{2}{|c|}{2000} \\
\hline & & Abs. & $\%$ & Abs. & $\%$ & Abs. & $\%$ \\
\hline San Salvador & 19 & 17 & 89.5 & 13 & 68.4 & 13 & 68.4 \\
\hline Santa Ana & 13 & 9 & 69.2 & 10 & 76.9 & 10 & 76.9 \\
\hline San Miguel & 20 & 13 & 65.0 & 14 & 70.0 & 14 & 70.0 \\
\hline La Libertad & 22 & 9 & 40.9 & 17 & 77.3 & 16 & 72.7 \\
\hline Usulután & 23 & 18 & 78.3 & 19 & 82.6 & 19 & 82.6 \\
\hline Sonsonate & 16 & 12 & 75.0 & 14 & 87.5 & 14 & 87.5 \\
\hline La Unión & 18 & 10 & 55.6 & 13 & 72.2 & 9 & 50.0 \\
\hline $\mathrm{La} \mathrm{Paz}$ & 22 & 13 & 59.1 & 17 & 77.3 & 18 & 81.8 \\
\hline Chalatenango & 33 & 18 & 54.5 & 21 & 63.6 & 20 & 60.6 \\
\hline Cuscatlán & 16 & 3 & 18.8 & 12 & 75.0 & 13 & 81.3 \\
\hline Ahuachapán & 12 & 11 & 91.7 & 12 & 100.0 & 11 & 91.7 \\
\hline Morazán & 26 & 20 & 76.9 & 14 & 53.8 & 22 & 84.6 \\
\hline San Vicente & 13 & 9 & 69.2 & 9 & 69.2 & 10 & 76.9 \\
\hline Cabañas & 9 & & 55.6 & 7 & 77.8 & 6 & 66.7 \\
\hline Total & 262 & 167 & 63.7 & 192 & 73.3 & 195 & 74.4 \\
\hline
\end{tabular}

Fuentes: Elaboración propia según resultados en TSE (200(0)), (2000)c), (1997)

personal del alcalde. ¿Y qué pasa con los otros concejales? ¿Están allí solo para obedecer las disposiciones del alcalde? Éxitos y fracasos recaerán sobre la persona del alcalde. Este arreglo institucional favorece el protagonismo de los alcaldes de las ciudades más importantes del pais, especialmente el de San Salvador. Es más fácil que un ciudadano de Morazán conozca al alcalde de San Salvador que un ciudadano de San Salvador conozca al alcalde de Perquín. La disputa por la alcaldía de San Salvador se convierte en un anuncio de la disputa presidencial". José Napoleón Duarte y Armando Calderón Sol fueron alcaldes de San Salvador antes de llegar a ser presidentes de la República. No estaría fuera de toda lógica que el actual alcalde capitalino fuera propuesto como candidato presidencial para las elecciones de 2004. Es indudable que San Salvador, como capital del país, tiene más importancia política que cualquier otro municipio. También allí se concentra el poder económico. Pero esto no debería traducirse en que un ciudadano capitalino luviese mayores probabilidades de ser candidato y luego presidente de la República en comparación con cualquier otro ciudadano del resto del país. Esto significaría que no todos los ciudadanos son iguales en términos políticos.

Finalmente, la vigencia práctica de las harreras establecidas para las elecciones presidenciales y legislativas para las elecciones municipales impide la existencia de partidos de ámbito local. Si un partido necesita un número de afiliados mayor al 3 por ciento de los votos válidos de la última elección presidencial es imposible que haya partidos locales en municipios cuya población está muy por debajo de ese 3 por ciento. Esta barrera puede ser comprensible cuando la disputa es de órganos de poder en el nivel nacional. Pero, ipor qué tendría que regir cuando la competencia está planteada en niveles inferiores? Podría ocurrir que realmente se trate de un problema de interpretación del artículo 159 del Código Electoral, en el senti-

31. En esto también intervienc el papel de los medios de comunicación social, especialmente la televisión que llcva la imagen del alcalde de San Salvador a la mayor parte del pais. 
do que se ha entendido el 3 por ciento de los volos en el nivel nacional cuando perfectamente podría entenderse referida a la circunscripción donde se disputa la elección. Así bien podría interpretarse como 3 por ciento de volos en la circunscripción departamental o municipal. Esta posibilidad estaría implicando más bien un problema de interpretación tradicional del citado artículo antes que una barrera legal explícitamente establecida. Creo que, en este caso, los especialistas en el derecho lienen un espacio abierto para el debale jurídico. Como no es mi especialidad paso a otro punto.

\subsection{La organización del evento electoral}

En este apartado quiero referirme a una serie de elementos que, aunque no forman parte del sistema electoral -en el sentido más restringido del término-, inciden en el caudal de volos que luego son transformados en escaños. Algunos tienen que ver con los tres procesos electorales en general y otros se refieren a un proceso en específico. Las fuentes para este análisis son la Constitución Política y el Código Electoral.

En primer lugar, creo que hay algo que decir sobre el calendario electoral. De acuerdo con la Constitución Política, las elecciones presidenciales se realizan cada cinco años (Art. 154), las elecciones de diputados cada tres años (Art. 124) y las de concejos municipales también cada tres años (Art. 202). Estas disposiciones implican que cada quince años coinciden los tres tipos de elecciones - como en 1994. A lo largo de ese período se celebrarían 5 votaciones para diputados, 5 para concejos municipales y 3 para presidente y vicepresidente de la República. Sin embargo, dado que las elecciones legislativas y municipales son simultáneas, podemos hablar de la celebración de 8 procesos electorales. Si comparamos esta cantidad de elecciones con lo que ocurre por ejemplo en Costa Rica u Honduras, donde se tienen elecciones generales cada cuatro años, en un período de 16 años se habría celebrado el doble de elecciones en El Salvador $^{32}$. Esta alta frecuencia supone mayores gastos financieros pero además un mayor desgaste procedimental y cansancio en la ciudadanía. ¿Qué otra cosa no sucede cuando tenemos elecciones en años seguidos? Esto es lo que ocurrirá en el 2003 y el 2004 cuando se celebren elecciones legislativas y municipales, en el primer año, y luego elecciones presidenciales en el segundo año ${ }^{33}$. Bajo esta calendarización electoral no hay que extrañarse que los partidos posean más una visión electoralista del juego político. Perfectamente podría aplicárseles la definición que ya hace muchos años propuso A. Downs sobre los partidos políticos cuando decía que éstos actuaban de manera instrumental. No buscarían el apoyo elecloral para llevar adelante políticas, sino que ofrecerían políticas para garantizarse el mayor apoyo electoral que les permita mantenerse o alcanzar el poder (Downs, 1973).

El tema de la calendarización electoral va de la mano del tema de la posibilidad de reelección. Los artículos de la Constitución Política, ya citados, establecen que diputados y concejales municipales pueden ser reelegidos, pero no el presidente. Del vicepresidente no se dice nada con lo cual ha quedado abierla la posibilidad de darle continuidad a las políticas implementadas por una administración si quien ha fungido como vicepresidente se convierte en la siguiente elección en presidente. Desde este punto de vista, tendríamos una razón a favor de disminuir el periodo presidencial a cuatro años y aumentar el periodo legislativo y municipal a cuatro años también para tener elecciones generales y disminuir la frecuencia de votaciones. Ahora bien, puede ser objeto de debate la reelección de los diputados y hasta cuántas veces se debería permitir. Uno podría pensar que cuantas más veces se permila que un dipulado pueda ser reelegido mayor será el deseo del diputado a permanecer en funciones en la Asamblea Legislativa. Este diseño institucional puede favorecer las tendencias oligárquicas dentro de los partidos políticos por las variadas razones que ya señaló en su debido momento Michels (1969). Entre otras causas este autor señaló la división del trabajo y la especialización: "Dondequiera que esa división del trabajo prevalece hay necesariamente especialización, y los especialistas se hacen indispensables" (Michels, 1969 , p. 139). Además, la especialización requiere tiempo. El funcionario debe familiarizarse con el trabajo que realiza y debe sentir la seguridad de que no será destituido en cualquier momento. Las

32. Si la comparación la hiciésemos con Guatemala resultaría que en El Salvador la frccucncia de cventos clectorales es casi el triple, pues en el primer pais las elecciones se celebran cada 5 años.

33. Situaciones semejantes ocurrieron en 1984-1985 y 1988-1989. 
designaciones por poco tiempo en un cargo pueden ser democráticas, dice Michels, pero, en sus aspectos técnicos y psicológicos, pueden ser muy poco prácticas. Así pues, el miembro del partido que llega a ser diputado durante varios períodos puede verse tentado a no querer abandonar su curul. Su especialización obstaculiza la circulación de otros miembros del partido por los puestos de elección pública.

Por otra parte, la calendarización electoral nos remite también al tema de la integración del Tribunal Supremo Electoral (TSE). Según el artículo 208 de la Constitución y el 59 del Código electoral, cinco magistrados forman el TSE y su período en funciones es de 5 años marchando a la par de las elecciones presidenciales. De los cinco magistrados, tres corresponden a los tres partidos o coaliciones con más votos, mientras que los otros dos son elegidos por ternas propuestas por la Corte Suprema de Justicia y elegidos con los $2 / 3$ de los votos de los diputados. Por lo estipulado en el artículo 59, en la práctica, no cualquier ciudadano -aún estando en pleno goce de sus derechos civiles y políticos- puede ser magistrado del TSE. Existen dos llaves institucionales: $(a)$ ser propuesto por un partido político o coalición y (b) cumplir con los requisitos para ser magistrado de las Cámaras de Segunda Instancia. En la práctica esto resulta en que o bien se es miembro de un partido político o bien se es abogado.

Si bien es cierto que el TSE goza legalmente de autonomía en materia electoral respecto de cualquier órgano del Estado, en la práctica puede ver limitada dicha autonomía por presiones partidistas. Tres Magistrados son miembros de partidos políticos y los otros dos son elegidos por los diputados (que también son miembros de partidos políticos). No estoy afirmando que el TSE esté supeditado a intereses partidistas, pero el diseño institucional adoptado abre espacios para la influencia de los partidos. La imposibilidad práclica del TSE de parar la propaganda electoral anticipada en las elecciones del 2000 por parte de los partidos ARENA y FMLN dio mucho que decir al respecto. Es cierto que al final se multó a ambos institutos políticos, pero la propaganda ya había sido hecha durante varios días pese a las exhorlaciones del TSE para suspenderla. Aunque no tengo datos en este momento para mostrar evidencia, no sería imposible mostrar que esta influencia partidista penetra otros niveles del TSE. Allí están las llamadas "claves". Puesto en otros términos, uno podría preguntar sobre el criterio de selección de los empleados del TSE y no sería extraño encontrarse con que en no pocos casos aparece la afinidad o militancia partidista. Tomando en cuenta lo que ha sido la historia de la práctica política en el país, este fenómeno es del todo comprensible. La integración de las instituciones políticas no están ajenas a la influencia y penetración de las organizaciones políticas para garantizarse algún nivel de influencia o de control sobre las decisiones allí adoptadas. El problema en el caso del TSE es que la participación de los partidos al interior de "la máxima autoridad en materia electoral" los convierte en jueces y partes.

Ya que en el párrafo anterior mencioné la problemática que se presentó en torno a la propaganda electoral en el 2000 , vale la pena señalar lo siguiente. Según la Constitución Política, la propaganda para las elecciones presidenciales no puede hacerse sino a partir de cuatro meses antes de las votaciones; para el caso de las elecciones legislativas, dos meses antes y para las de concejos municipales, un mes antes (Art. 81). Cuando las tres elecciones coinciden, dado que los partidos son de ámbito nacional, la propaganda electoral presidencial termina siendo en la práctica propaganda para los otros dos tipos de elecciones. Además, como las elecciones legislativas y municipales son simultáneas, la propaganda para las primeras termina siendo propaganda para las segundas. El carácter nacional de los partidos permite que la propaganda para elecciones nacionales viole en la práctica la prohibición para hacer propaganda para elecciones municipales. Habría que preguntarse lambién si cuatro o dos meses no constituyen demasiado tiempo de bombardeo propagandístico para la ciudadanía.

Un tema que ya hace algún tiempo flota en el aire es el de las candidaturas a través de los partidos. Según el artículo 85 de la Constitución Política, los partidos políticos "son el único instrumento para el ejercicio de la representación del pueblo dentro del Gobierno". Se entiende aquí por Gobierno tanto al Órgano Ejecutivo como al Órgano Legislativo, asi como también el Gobierno tanto nacional como municipal. En lo que al Ejecutivo se refiere no hay que olvidar que únicamente los puestos de presidente y vicepresidente son de elección pública. El resto del gabinete de gobiemo es nombrado por el Presidente. Esta situación abre la 
posibilidad que personas que no militan en partidos puedan acceder a puestos en el Gobierno. Tal vez no sea el escenario más frecuente, pero la posibilidad existe.

En el caso del acceso a los escaños legislativos o dentro de los concejos municipales, no hay posibilidad de candidaturas independientes. Aunque ello no significa necesariamente que ciudadanos sin afiliación partidista no puedan convertirse en diputados o concejales en los municipios. La participación de miembros de Iniciativa Ciudadana en el concejo municipal de San Salvador, entre 19972000 y 2000-2003, muestran esta posibilidad. Más difícil es el acceso independiente a los escaños legislativos dado el control partidista en la elaboración de las listas de candidatos. Sin embargo, creo que es necesario analizar la participación independiente desde lo que ha sido la práctica de la representación política en el parlamento. La existencia de diputados independientes en algunas legislaturas no puede ser pasada por

La integración de las instituciones políticas no están ajenas a la influencia y penetración de las organizaciones políticas para garantizarse algún nivel de influencia o de control sobre las decisiones allí adoptadas. ría ejercer cierto balance entre los intereses partidistas en juego y unos supuestos intereses más generales de la ciudadanía. En el caso de la Asamblea Legislativa, una pretensión de este tipo supondría una cuota lo suficientemente alta de escaños independientes para ejercer ese "balance". En caso contrario habría que aceplar la verdad del dicho popular: "una golondrina no hace invierno". Por otro lado, ¿quién o qué garantizaría que el comportamiento de los representantes independientes expresaría los supuestos intereses más generales? ¿cómo podría pedirsele cuentas a los que precisamente se definen como "independientes"? Además, iquiénes podrían realmente acceder a candidaturas independientes? Considero que un examen más sistemático del comportamiento realmente existente de los diputados que se declararon independientes en legislaturas anteriores podría arrojar elementos de juicio para poder responder estas y otras preguntas similares. Se trata de una tarea pendiente. alto. Incluso en algunos momentos se ha llegado a constituir además de las fracciones de los partidos mayoritarios, grupos mixtos que han incluido a diputados de partidos minoritarios e independientes. ¿De dónde han salido éstos? De la deserción o expulsión de diputados de los partidos que les llevaron como candidatos en la elección. Es entonces cuando hacen su aparición los diputados independientes.

Más importante que la discusión sobre las candidaturas independientes es la discusión sobre el control de la ciudadanía sobre sus representantes y gobernantes. Las actuales demandas de algunos ciudadanos a favor de las candidaturas independientes surgen justamente ante la incapacidad de la ciudadanía para ejercer control sobre el comportamiento de sus representantes políticos y de las decisiones que éstos adoptan. El control se ha reducido al ejercicio del voto y al llamado castigo electoral a los partidos que llevaron como candidatos a aquellos representantes cuyo comportamiento se rechaza. La presencia de representantes políticos independientes de los partidos pretende-
Para no hacer más largo este diagnóstico, finalmente voy a referirme brevemente al tema de la llamada deuda política. El artículo 210 de la Constitución Política fija su objetivo en promover la libertad e independencia de los partidos ${ }^{34}$. ¿ $\mathrm{Li}-$ berlad e independencia respecto a quiénes? No lo dice la Constitución, pero se supone que se trata de poderosos grupos de interés que podrían comprar la "voluntad" de los partidos políticos. El financiamiento particular de los partidos buscaría la traducción política del poder económico de diversos grupos sociales. Aquel grupo o aquellos grupos con más poder económico podrían influir más sobre los partidos y el sistema político en su conjunto. El financiamiento público pretendería contrarrestar esta tendencia. Se supone que al proporcionarle fondos públicos a los partidos se les está permitiendo que su existencia no dependa tanto de grupos económicos privados. Se estaría buscando brindarles un margen de autonomía. Ahora bien, ¿cómo funciona este mecanismo de financiamiento público de los partidos?

34. La normativa de la deuda política está establecida en los arlículos 187 a 195 del Código Electoral. 
Según el Artículo 187 del Código Electoral, los partidos reciben una cierta cantidad de dinero por cada voto válido que obtengan en la elección respectiva. Esto quiere decir que tienen derecho a recibir fondos públicos sólo los partidos que hayan participado en la contienda electoral (Art. 188). Como es evidente que antes de las elecciones no se sabe cuántos votos obtendrá cada partido se les otorga un anticipo (Art. 190). Pasadas las elecciones, se hace el respectivo balance y algunos partidos reciben más dinero - porque la cantidad de votos que acumularon sobrepasa al equivalente del anticipo- y otros tienen que reintegrar parte del anticipo - porque sus volos no cubren el monto de éste (Art. 192). En la medida que cuantos más votos obtiene un partido, mayor es el financiamiento público que recibe, este diseño institucional favorece a los partidos mayoritarios. Es cierto que por cada voto se recibe la misma cantidad de dinero, pero resulta que al final de cuentas se cumple aquel otro dicho de que: "a quien más tiene más se le dará"’.’. Por otro lado, ¿hasta que punto es verdad que el financiamiento público fomenta la libertad e independencia de los partidos? Si la respuesta a esta pregunta negara lal libertad e independencia resultaría entonces que a quien con mayor poder económico traduce dicho poder en poder político, el financiamiento público le olorga otro plus de poder económico que incrementa su poder político. En estas condiciones, el juego politico se desnuda como juego por el poder. Lo que importará entonces es obtener mayor poder. Éste aparece como el fin último de la política. Nada más lejos de aquella concepción de la política como servicio.

\section{Una agenda de reforma}

Hasta aquí he presentado un análisis que considero suficiente para sustentar algunos puntos de agenda para la reforma electoral. No se trataba de hacer un análisis exhaustivo, pues soy consciente de que hay otros temas imporlantes que no consideré. Además, el espacio aquí disponible impone límites al análisis posible. Ahora quiero pasar a la parte propositiva. Esta larea casi siempre resulta ser la parte más difícil. Estas propuestas intentan recoger los dos objetivos políticos señalados al inicio de este trabajo: mejorar la representatividad de la representación política salvadoreña y acercar los representantes a los representados mediante mecanismos que permitan un mayor control de los segundos sobre los primeros.

Un primer punto de agenda apuntaría a los diversos principios de representación en los que se basan nuestros actuales sistemas electorales. Desde este punto de vista habría que modificar el tipo de representación mayoritaria que rige para los concejos municipales y adoptar un sistema proporcional. Esto permitiría una mejor representatividad de los concejos y la presencia de diversos intereses en la gestión municipal. Además contribuiría a la despersonalización de la disputa políti$\mathrm{ca}$, especialmente si la elección no se plantea como elección del alcalde o alcaldesa sino de todo el concejo municipal. Este último sería el encargado de elegir al jefe edilicio. Incluso podría experimentarse en este nivel el recurso al voto preferencial para darle un mayor protagonismo a los electores frente a las propuestas partidistas. Una medida en esta dirección implicaría también la adopción de una lista cerrada, pero no bloqueada.

También debería ser objelo de reforma la fórmula decisoria empleada en las elecciones presidenciales. La recomendación aquí es pasar de la mayoría absoluta y segunda vuelta a una mayoría relativa del 40 o 45 por ciento de los votos válidos más una segunda vuella si fuese necesario.

El análisis de la proporcionalidad del sistema empleado en las elecciones legislativas me permite recomendar su mejora, es decir, incrementar su nivel de proporcionalidad. Es imposible eliminar los efectos desproporcionales. Sin embargo, pueden reducirse y una de las vías es mediante el rediseño de las circunscripciones electorales. En la simulación hecha en el Cuadro 8 presenté dos alternativas de rediseño. $\mathrm{O}$ bien se reducen todas las circunscripciones actuales a una sola circunscripción de carácler nacional, o bien se agrupan circunscripciones ya existentes en circunscripciones regionales. Particularmente me inclino por esta última opción, pucs incluye el criterio de acercar los dipu-

35. Scría interesantc indagar también sobre cl cumplimicnlo a cabalidad del reintegro de la parte del anticipo a la que no tienen derecho los partidos. Aquí, como en otros puntos ya señalados, parece no haber rendición de cuentas hacia la ciudadanía, que es la que finalmente financia a los partidos a través de sus impucstos. 
tados a los electores. Además se le daría mayor fuerza política a los diputados departamentales en la medida que pueden sumar votos por regiones.

Junto a la anterior medida habría que buscar reducir los problemas de malapportionment. De ninguna manera se trata de una medida fácil, pues supone contar con la distribución exacta de los electores a lo largo y ancho del país. Creo que tampoco bastaría esto, pues, al final de cuentas, la proporción que determina el valor del voto es más bien la relación votos válidos/diputados. Habría que pensar en la posibilidad de tener una Asamblea Legislativa con un número de diputados variable de acuerdo con el total de votos que se registran en cada circunscripción. Otra alternativa sería calcular cocientes electorales promedios según los niveles de votación en las circunscripciones. En la medida que las circunscripciones tengan cocientes electorales cercanos podría aproximarse un único cociente electoral promedio para tales circunscripciones. Si bien es cierto que no se eliminaría totalmente el malapportionment, probablemente podría reducirse significativamente ${ }^{3 /}$.

El tema de las candidaturas por circunscripciones va ligado al tema de las formas de la candidatura. Si lo que se pretende es acercar a diputados y electores habría que darle mayor prolagonismo a éstos en la elaboración de las listas y no solo en la votación. Una de las medidas en este sentido sería la selección de los candidatos partidistas a través de elecciones primarias. Las posibilidades de los aspirantes a las candidaturas ya no dependerían solo de las decisiones de las cúpulas partidistas, sino que tendrían que contar con el aval de los potenciales electores del partido en cuestión. Ya esta situación se convertiría en un anclaje institucional entre votantes y candidatos que puede prolongarse más allá de un período legislativo. La postulación nuevamente de cualquier candidato estaría dependiendo de la percepción que sus votantes tengan de su gestión. Solo entonces le darían un merecido premio postulándolo de nuevo frente al resto del electorado.

Por otro lado, habría que regular explícitamente que los candidatos para diputados y concejales vivan y conozcan la problemática de sus circunscripciones. Habría que evitar candidaturas de per- sonas que son ajenas a la población respectiva. Un anclaje institucional en este sentido sería permitir la existencia de partidos regionales o municipales. En otras palabras, habría que disminuir el monopolio de la representación política que ostentan los partidos de ámbito nacional. Si las circunscripciones electorales constituyen el fundamento último para el conteo de los votos y el reparto del poder en ellas, habría que ser consecuentes permitiendo la existencia de partidos que compiten solo en circunscripciones específicas. Esto implicaría la modificación de las barreras legales para la inscripción de los partidos políticos ante el TSE.

También habría que revisar la conveniencia de mantener atada la elección de los diputados de la circunscripción nacional a la suma de votos a través de todas las circunscripciones departamentales. Habría que pensar en la necesidad de una papeleta de votación para la circunscripción nacional independiente de las respectivas papeletas que ya se utilizan en las circunscripciones departamentales o regionales - si se adoptara una propuesta de rediseño como la ya señalada en párrafos anteriores.

En cuanto a temas organizativos, considero que es necesario bajar el ritmo electoral. Para ello podría aumentarse el período legislativo y municipal a cuatro años y disminuir el presidencial en un año. De esta manera tendríamos elecciones generales cada cuatro años y habríamos disminuido la cantidad de elecciones a la mitad de las que actualmente se celebran cada 15 años. También se disminuirían los costos que implica la realización de cada proceso elecloral y en cierta forma el hambre de votos de los partidos políticos en los períodos entre elecciones. Si actualmente la celebración de elecciones legislativas y municipales a medio período presidencial sirven de barómetro político electoral, la simultaneidad propuesta para los tres procesos electorales eliminaría esta posibilidad. Si se quiere conservar este barómetro habría que pensar en otros mecanismos que sirvan como equivalentes funcionales. En tal sentido podría fijarse la celebración de elecciones municipales, en períodos intercalados con los períodos presidenciales, en las cuatro ciudades más importantes del país - seleccionando una ciudad por cada circunscripción regional propuesta anteriormente.

36. Por lo menos debería ajustarse la actual distribución de dipulados por departamento para que al menos se cumpla que a mayor población departamental, mayor sca la cuota de represcntación que debe asignárscle. 
Por otra parte, la simultaneidad de los tres procesos electorales debería ir acompañada de una nueva regulación de la propaganda política. Se podría reducir el tiempo de propaganda electoral a dos meses, tal como actualmente se hace para las elecciones legislativas que como las presidenciales son de ámbito nacional. No habría razón para una prolongada campaña electoral de cuatro meses. Consecuentemente con esta medida que estaria reduciendo el tiempo de exposición al bombardeo propagandístico a los electores se sometería a un menor desgaste el procedimiento democrático de las elecciones.

Otro tema que habría que retomar es el de las candidaturas independientes. Al respecto creo que es un tema que necesita mayor espacio para su tratamiento sistemático. Podría haber argumentos a favor y en contra. No creo que sea automáticamente una mejor alternativa a las candidaturas a través de los partidos. Sin embargo considero que podría experimentarse en el nivel de las elecciones municipales como ya se hace en Guatemala, a través de los comités cívicos, y como hasta hace poco se hacía en Nicaragua, a través de las asociaciones de suscripción popular. Uno de los criterios que debe regir la discusión al respecto debería ser el de la viabilidad y ejercicio del control ciudadano sobre las decisiones y acciones adoptadas por los representantes políticos independientes.

El tema de las candidaturas, independientes o no, está vinculado al tema del financiamiento de quienes postulan tales candidaturas. En la medida que los partidos políticos gozan de un monopolio constitucional de la representación política, el financiamiento estatal es para los partidos. Ya hemos visto cómo en la práctica son los partidos más grandes los que más se benefician con este tipo de financiación. ¿Qué pasaría si se introducen las candidaturas independientes? ¿Quiénes tendrían en realidad posibilidades de postularse como candidatos? ¿De dónde obtendrían los fondos para financiar su campaña? ¿No implicaría esta financiación algún tipo de compromiso con las fuentes de esos fondos? ¿Dónde quedaría entonces el carácter independiente de la candidatura? Son demasiadas preguntas como para dar por sentada una supuesta superioridad de las candidaturas independientes sobre las candidaturas partidistas para mejorar la calidad de la representación política. Probablemente habría que pensar en medidas alternativas dirigidas a regular la actividad de los partidos y de sus miembros, en tanto se trata de organizaciones de carácter público con aspiraciones al ejercicio de funciones públicas y qué reciben fondos públicos para su manutención. Avanzar en una ley de partidos resulta muy importante en este sentido. Se trata de una tarea en la que no habría que dejar solos a los partidos. Difícilmente éstos van a atentar contra sus intereses partidistas. De allí que sea necesaria la acción ciudadana en tanto los ciudadanos son también actores políticos involucrados en el juego político.

Sobre la integración del TSE también habría algo que decir. Si no fuese posible la despartidización del TSE habría que abrirle espacios a otros actores que no provienen de los partidos. Quizá aquí sea un escenario donde sea importante la presencia de ciudadanos independientes que hagan contrapeso a los partidos políticos y sus intereses. Estos ciudadanos bien podrian provenir de agrupaciones civilistas o bien podrían estar allí a título individual. En este sentido, habría que aumentar la cantidad de magistrados del TSE. Ya he argumentado que la presencia de dos magistrados propueslos por la Corte Suprema de Justicia no garantiza su independencia respecto de los partidos. Pero aunque asi fuera, siempre están en desventaja de dos contra tres en el Órgano Colegiado.

Finalmente, también habría que colocar como punto de agenda el voto de los salvadoreños en el llamado "Departamento 15". Se trata de otro punto que debe ser discutido ampliamente, pues habría argumentos a favor y en contra también. Habría que definir cuál sería el objetivo político a perseguir con una medida a favor del voto de los "hermanos lejanos". No creo que baste con decir que como salvadoreños tienen derecho a votar independientemente de dónde estén viviendo. Porque ante este supuesto derecho habría que preguntar si debería permilírseles influir en los destinos de los salvadoreños que están dentro del país aguantando directamente los efectos de las decisiones y acciones de quienes ocupan los cargos de elección pública. Además, como hay tres o cuatro tipos de elecciones en el pais, habría que preguntarse si el voto de los hermanos lejanos tendría que permitirse en todos los tipos de elección y en su viabilidad. Me atrevería a proponer una solución intermedia a la problemática del voto de los salvadoreños en el extranjero. Dada la magnitud de estos salvadoreños me pregunto si no sería mejor pensar en una circunscripción más para las 
elecciones legislativas y asignarle una cuota de representación a los salvadoreños en el esiranjero dentro de la Asamblea Legislativa. Sin embargo, y con esto termino, creo que se trata de un tema que amerita un debate nacional.

\section{Bibliografía}

Artiga-González, Álvaro (2000a). "Electores, partidos y la caja de Pandora". En ECA, 617. San Salvador: Universidad Centroamericana José Simeón Cañas, pp. 267-288.

Artiga-González, Alvaro (2000b). "El comportamiento electoral municipal en El Salvador". En Realidad, 74. San Salvador: Universidad Centroamericana José Simeón Cañas, pp. 167-183.

Artiga-González, Álvaro (1997). "Efectos de los sistemas electorales en El Salvador". En Realidad, 58. San Salvador: Universidad Centroamericana José Simeón Cañas, pp. 333-346.

Artiga-González, Álvaro (1996). "Sistemas electorales en El Salvador". En Realidad, 54. San Salvador: Universidad Centroamericana José Simeón Cañas, pp. 765-788.

DIGESTYC (1996). Proyección de la población de El Salvador. San Salvador: Dirección General de
Estadística y Censos, Ministerio de Economía.

Downs, Anthony (1973). Teoría económica de la democracia. Madrid: Aguilar.

Mendoza Orantes, Ricardo (2000). Constitución con sus reformas 2000. San Salvador: Jurídica Salvadoreña.

Michels, Robert (1969). Los partidos políticos. Un estudio sociológico de las tendencias oligárquicas de la democracia moderna. Buenos Aires: Amorrortu.

Nohlen, Dieter (1994). Sistemas electorales y partidos políticos. México: Fondo de Cultura Económica.

Nohlen, Dieter (1993). Los sistemas electorales en América latina y el debate sobre reforma electoral. México: Universidad Nacional Autónoma de México, UNAM.

Taagepera, Rein y Shugart, Matthew (1989). Seats and Votes. New Haven: Yale University Press.

TSE (2000a). Código Electoral. San Salvador: Edit-TSE.

TSE (2000b). Guía elecciones 2000. San Salvador: Edit-TSE.

TSE (2000c). Memoria especial elecciones 2000 . San Salvador: Edit-TSE. 